\title{
Secular Stagnation, Financial Frictions, and Land Prices
}

\author{
Zhifeng Cai * \\ Rutgers University
}

November 14, 2018

\begin{abstract}
This paper explores a model in which large transitory financial shocks can generate persistent slumps in output, land prices, and interest rate. The propagation originates from high sensitivity of land prices with respect to fundamental, which is achieved by a land consumption channel that exploits the high complementarity of land services and consumption in households' preference. When this complementarity is disciplined by micro-level evidence, the unique recursive equilibrium features an S-shaped law of motion for capital with two locally stable steady states. Small shocks move the economy around the unconstrained steady state whereas large transitory financial shocks push the economy into the constrained steady state at which low interest rate makes firm unwilling to save out of the financial friction, leading to a secular stagnation.
\end{abstract}

*E-mail: zhifeng.cai@rutgers.edu. The author is grateful to V.V. Chari and Jonathan Heathcote for invaluable guidance. The author also thanks Manuel Amador, Anmol Bhandari, Xavier Bianchi, Roberto Chang, Kyle Herkenhoff, Nir Jaimovich, Urbann Jermann, Larry Jones, Todd Keister, Wenzel Lee, Neil Mehrotra, Guido Menzio, Christopher Phelan, Vincenzo Quadrini, Mathieu Taschereau-Dumouchel, Hazel Tuzel, and seminar participants at Wharton Penn, USC Marshall, Rutgers University, Federal Reserve Bank of Minneapolis, Public Workshop and Mathematical Economics Workshop at the University of Minnesota for helpful comments. 


\section{Introduction}

Recovery from a financial crisis can be painfully slow, even if the crisis itself does not last long. This is especially the case when the crisis is compounded with a collapse of the real-estate sector. A prominent example is the 2008 Great Recession, during which both the financial and the real-estate sector experienced tremendous distress, followed by persistent slumps in the values of housing and land. ${ }^{1}$ The crisis also featured much greater declines in macroeconomic activities and a much slower recovery relative to previous postwar recessions (Figure 1), a phenomenon termed "secular stagnation".

The joint occurrence of financial market distress, real-estate price collapses, and secular stagnation is not unique to the Great Recession. Looking back at historical stagnation events such as the 1990 Japanese financial crisis and the 1930 Great Depression, both are renowned for dramatic collapses of the financial and real-estate sector, as well as the economic stagnation that followed it. Formal econometric evidence (Cerra and Saxena, 2008; Reinhart and Rogoff, 2009a,b) also shows that financial crisis recessions tends to be deeper and more protracted, and are often associated with prolonged asset market collapse. Jordà, Schularick, and Taylor (2015) documents that crises accompanied with real-estate price bust tends to be followed by particularly slow recoveries.

These empirical patterns suggest that financial frictions and real-estate price collapses play important roles in propagating transitory crisis events into prolonged economic stagnations. However, formal theories are lacking in this regard..$^{2}$ This paper fills this gap by proposing such a framework. ${ }^{3}$ The key idea of the paper is that strong propagation of recessions can be obtained if asset prices are sufficiently sensitive with respect to economic fundamental (such as physical capital and household wealth); and this high sensitivity can be achieved by a "land consumption channel" which exploits the fact that land services are highly complementarity to consumption in households' preferences.

The land consumption channel refers to the fact that land, on top of being a production factor and a collateral asset, also serves a consumption role: it provides services (housing) valued by the households. If land services and consumption are highly complementary, households' demand

\footnotetext{
${ }^{1}$ It has been argued that the huge drop of housing price during the recession is largely corrections to the prerecession housing price boom. Yet despite the pre-recession acceleration, there were still big declines in housing prices relative to its trend after the Great Recession (see figure 13 for house prices and figure 14 for land prices constructed following Davis and Heathcote (2007)).

${ }^{2}$ In fact, some have argued the opposite: that models with financial frictions cannot generate strong propagation quantitatively (Kocherlakota 2000; Cordoba and Ripoll 2004). For a survey that discusses this issue, see Quadrini (2011).

${ }^{3}$ The literature has explored the linkage between land (house) price dynamics and macroeconomic fluctuations(see, for example, Iacoviello, 2005 and Liu, Wang, and Zha, 2013). They do not explore implications of land price dynamics on secular stagnation, which is the focus of this paper. See related literature section for a more detailed discussion.
} 

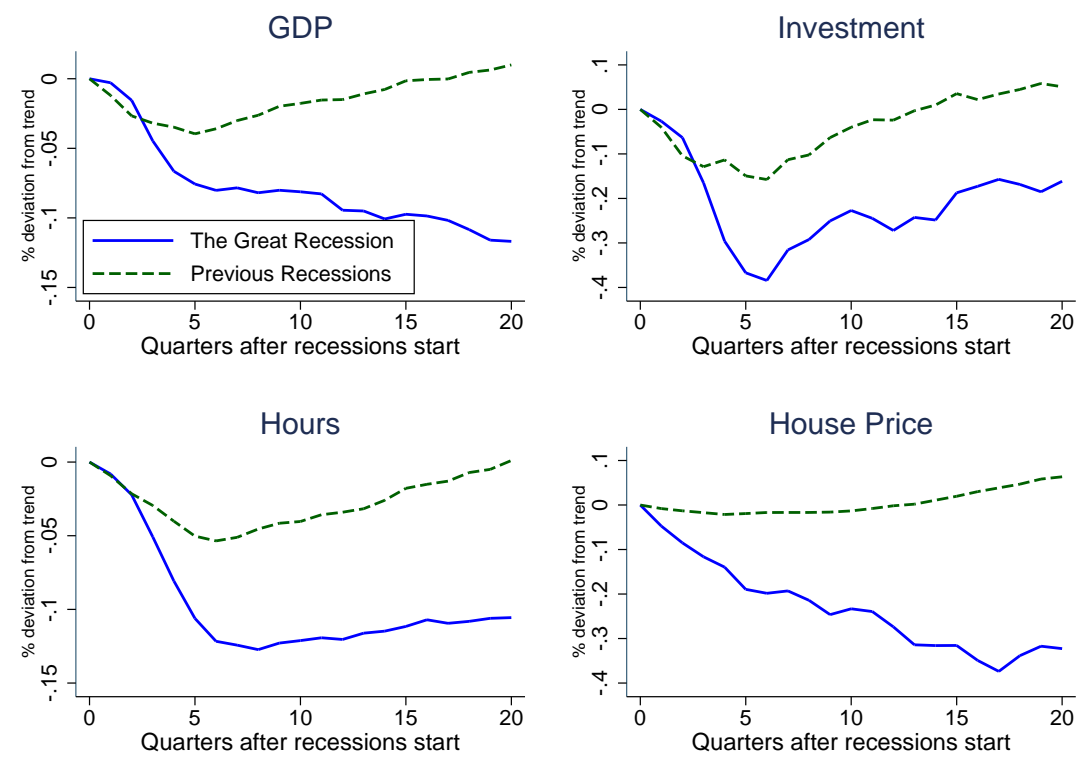

Note: This figure plots linearly detrended aggregate variables in the five-year window following the Great Recession (solid blue curve) and previous recessions (dashed green curve). Previous recessions include the 2000 recession, the 1990 recession, the 1981 recession, the 1973 recession, and the 1960 recession. Starting point is normalized to 0. GDP is the real GDP per capita. Investment is the real private gross investment. Labor is the total hours available from U.S. Bureau of Labor Statistics. Housing price is the Case-Shiller real home price index. Following an average postwar recession, major macroeconomic variables fully recovered in five years. Yet, the impact of the Great Recession is much more persistent: GDP and housing price kept declining relative to trends; Labor barely recovered; Investment recovered somewhat but was still 20 percent below trend five years after.

Figure 1: Great Recession vs. Other Postwar Recessions

for land would be highly sensitive to economic fundamental, which determines consumption. As land is an important form of collateral asset, this high sensitivity strengthens the two-way feedbacks between borrowing capacity and macroeconomic conditions and opens the door to strong amplification and propagation.

The paper consists of a theoretical part and a quantitative part. First, I embed the mechanism into a standard neoclassic growth model. In the model, both the household and the firm are subject to collateral constraints and their borrowing capacities are linked to land holdings. This leads to interesting interactions between the land market and the financial market. I prove that, unlike standard models with a unique steady state, multiple steady states can arise in this environment if consumption and land services are sufficiently complementary in the household's preference. ${ }^{4}$ The unique law of motion for capital is S-shaped with multiple stationary points. While there is no room for self-fulfilling fluctuations, the model features interesting nonlinear responses to fundamental

\footnotetext{
${ }^{4}$ The source of the steady-state multiplicity, similar to Schmitt-Grohé and Uribe (2018), is an aggregate nonconvexity introduced through collateral constraints with endogenous asset prices. Unlike Schmitt-Grohé and Uribe (2018), in this framework there is no self-fulfilling fluctuations across the two steady states because they are indexed by different levels of capital accumulation and household wealth.
} 
shocks such as productivity and credit shocks. Small shocks tend to move the economy around the unconstrained steady state, which corresponds to the usual steady state of a standard growth model. Large negative financial shocks, like what was observed in 2008, push the economy into a constrained steady state in which both the household and the firm are permanently borrowingconstrained.

The property that the firm is permanently constrained does not result from exogenous restrictions on its capital structure,$^{5}$ but rather due to endogenous equilibrium forces that depresses both the land prices and the interest rates. In the model, the firm has a rich set of asset instruments from which it can choose to "grow out of" its borrowing constraint: it can accumulate land, physical capital, as well as financial asset. However, at the constrained steady state it has little incentive to do so: Land, due to its low value, does not serve as an effective tool to relax the collateral constraint. Capital is not very attractive either because of its low productive value, as the firm is constrained in financing working capital and hiring complementary labor. Lastly and perhaps most importantly, at the constrained steady state the returns to financial assets (interest rate) is low because the household's demand for credit is tightly constrained by the depressed land value. The low interest rate in turn implies little incentive for the firm to hold financial assets. ${ }^{6}$ Thus, the household's borrowing capacity matters for the firm because the more the household is able to borrow, the more financial asset the firm can accumulate. This relaxes the firm's collateral constraint and allows for more working capital financing and hence higher output.

The low interest rate plays an important propagation role as it makes the firm unwilling to save out of its borrowing constraint. This propagation role of low interest rate is novel relative to the previous literature on secular stagnation which primarily focused on demand side issues (Eggertsson et al., 2019; Benigno and Fornaro, 2018). Thus, the theory proposed here can be regarded as a supply-side story of secular stagnation (Summers, 2014), where the low interest rate contributes to persistent slumps of macroeconomy through the firm's balance sheet.

The second part of the paper quantifies the land consumption channel. The key parameter is the elasticity of substitution between consumption and land services in the households' utility, as this parameter governs how sensitive land price is with respect to economic fundamental. For the land consumption channel to matter quantitatively, we require a relatively low degree of substitutability between land services and consumption. What, then, is the empirically plausible value for this

\footnotetext{
${ }^{5}$ The literature has proposed various ways such restrictions can be imposed such as finite life span, differential discounting, or tax benefits of debt. See Quadrini (2011).

${ }^{6}$ Although at the constrained steady state the firm sector does lend to the household sector, it is still borrowingconstrained due to the working capital financing needs.
} 
elasticity of substitution parameter? While studies based on macro-level data typically find a value (slightly) greater than one (Davis and Martin, 2009 and Piazzesi, Schneider, and Tuzel, 2007), most works based on micro-level data and structural estimation typically find a value between 0.1 and 0.6 (Hanushek and Quigley, 1980, Flavin and Nakagawa, 2008, Siegel, 2008, Stokey, 2009, and Li, Liu, Yang, and Yao, 2016). ${ }^{7}$ The identification of micro-level studies mainly come from crosssectional moments such as state-level house prices and expenditure shares on housing. I calibrate the model using the value estimated by Li, Liu, Yang, and Yao (2016), which lies at the high end of micro estimates. Note that, the goal of this paper is not to provide new estimates, but to illustrate the importance of this parameter in the macro-finance literature, and hopefully stimulate more empirical research. I find that the unique recursive competitive equilibrium features an S-shaped law of motion for capital with multiple locally stable steady states.

I then use the model to address the following question: could a severe but relatively short-lived financial market disturbances like what was observed in 2008-2009 have long-lasting impact on the economy (Ohanian 2010)? To answer the question, I follow Jermann and Quadrini (2012) and consider exogenous tightening of agents' borrowing constraints (credit shocks) as a proxy of financial market distress. After calibrating the credit shocks to observed drops in land prices during the Great Recession, I find that the credit shock, albeit short-living, is sufficient to trigger a shift from the unconstrained good steady state to the constrained steady state, leading to a secular stagnation.

The simulation result with only credit shocks predicts that the economy would settle at the bad steady state with all macro aggregates converging to a permanently lower level. This is roughly in line with the data, but with some notable discrepancies (figure 1). First, detrended output seems to keep declining after the recession. Second, labor (hours) has a slow but steady recovery. I thus consider an extended model with additional layers of realism. First, I incorporate time-varying productivity into the model. This helps to explain the declining aggregate output as productivity growth has been weak since the end of the recession. Second, I incorporate a downward wage rigidity constraint. This serves two purposes. First, it accounts for the slow and gradual recovery of labor as the wage rate slowly adjusts over time. Second, it allows me to use a much lower value of Frisch elasticity of labor supply, in line with the micro estimates, and still allows for significant stagnation after the Great Recession. The extended model also allows me to decompose the sources of stagnation into two components, one due to the weak growth in productivity (Benigno and Fornaro 2018) and the other due to the internal propagation driven by the land consumption

\footnotetext{
${ }^{7}$ A notable exception is Bajari et al. (2013).
} 
channel. I conclude that both productivity decline and the land consumption channel are important drivers of the secular stagnation, with the latter playing more important role before 2013 and the impact of productivity decline picked up after that.

\section{Related Literature}

It is to my knowledge the first paper that explores the link between financial frictions and secular stagnation. It is related to two strands of literature: one on financial frictions and the other on secular stagnation. There is an extensive and rapid-growing literature on macroeconomic effects of financial frictions, pioneered by Bernanke and Gertler (1989) and Kiyotaki and Moore (1997). This paper draws on a series of papers that examines how land price dynamics contribute to business cycle fluctuations through financial frictions (for example, see Iacoviello 2005; Liu, Wang, and Zha 2013; Liu, Miao, and Zha 2016). Different from these papers, this paper focuses on explaining the secular stagnation. To this end it exploits the fact that consumption and land could be highly complementarity, which leads to steady-state multiplicity, in contrast to existing works featuring a unique steady state.

This paper also builds on recent works by Mendoza (2010), Jermann and Quadrini (2012), Bianchi (2016), and Bianchi and Mendoza (2018), in which collateral constraints not only affect business investment but also affects working capital. This helps strengthening the quantitative impact of collateral constraints as they have direct impact on production inputs. However, these papers do not consider land prices dynamics and the consumption role of land. Moreover, they all feature a unique steady state. This paper instead features multiple steady states and an S-shaped law of motion for capital. This macroeconomic nonlinearity introduced through occasionally binding collateral constraints is also related to Guerrieri and Iacoviello (2017).

As mentioned earlier, this paper is closely related to Schmitt-Grohé and Uribe (2018) in terms of the source of steady-state multiplicity. Schmitt-Grohé and Uribe (2018) argues, in the context of an open endowment economy with flow collateral constraints, that collateral constraints introduce aggregate non-convexities giving rise to multiple stationary equilibria and self-fulfilling fluctuations. Unlike Schmitt-Grohé and Uribe (2018), in this model there is no self-fulfilling fluctuations across multiple steady states, as different steady states are characterized by different level of capital accumulation. Relatedly, Liu and Wang (2014) illustrate that credit constraints can generate local indeterminacy around a unique steady state similar to an economy with increasing returns. In my model there are multiple steady states without local indeterminacy.

The paper is also related to the literature on Secular Stagnation. Benigno and Fornaro (2018) 
propose a notion of stagnation traps in which weak productivity growth interacts with zero lower bound and lead to a permanent liquidity trap. Eggertsson et al. (2016) and Eggertsson et al. (2019) propose a demand-driven explanation of the secular stagnation where persistently low natural rate of interest results from shocks that alter households' life-saving decisions. Complementarity to this literature, I propose a supply-side explanation of the secular stagnation. Shimer (2012) argues that with perfect real wage rigidities, transitory shocks cause permanent shift in real allocations. Kaplan and Menzio (2016) propose a model of shopping externalities with steady state multiplicity. Self-fulfilling fluctuations lead to persistent rise in unemployment, consistent with the Great Recession. Fajgelbaum, Schaal, and Taschereau-Dumouchel (2017) propose a theory of endogenous uncertainty and illustrates how large temporary shock can be propagated and have permanent impact. Taschereau-Dumouchel and Schaal (2016b,a) illustrate, using Global-game techniques, how coordination failures among firms lead to steady-state multiplicity in a unique recursive competitive equilibrium. Different from all these works, the economic mechanism in this paper works through financial frictions and land price dynamics, in line with historical evidences (Cerra and Saxena, 2008; Reinhart and Rogoff, 2009a,b; Jordà et al., 2015).

Lastly, an important feature of the model is that the household's borrowing capacity matters for production as it determines the firm's ability to accumulate financial assets. Thus, it is broadly consistent with Mian and Sufi $(2011,2014)$ who document that during the Great Recession, regions of the United States that experienced the largest declines in household debt and house prices also experienced largest drops in consumption and employment. It is particularly related to Giroud and Mueller (2017) who argue that firm's balance sheets are crucial in understanding the transmissions of household-side credit crunch.

\section{The Model}

In this section I introduce the land consumption channel into a standard real business cycle model. I then characterize the model and prove the main theoretical result of the paper that there exists multiple steady states if there is sufficient complementarity between land services and consumption.

There is a representative household and a representative firm owned by the household. The commodity space consists of consumption goods, physical capital, labor, and land. Land is modeled

as a factor in fixed supply $\bar{L}$. The household's utility depends on consumption, labor and land service (housing). Goods production requires capital, labor and land. Both the household and 
the firm can be potentially borrowing constrained and they can use land and capital as a form of collateral.

Firm Sector The representative firm produces goods using capital, labor and land as inputs. The production function is given by:

$$
F\left(z_{t}, k_{t}, n_{1 t}, l_{1 t}\right)=z_{t}\left[l_{1 t}^{\gamma} k_{t}^{1-\gamma}\right]^{\alpha} n_{1 t}^{1-\alpha}
$$

where $z_{t}$ denotes the level of productivity, $k_{t}, n_{1 t}$, and $l_{1 t}$ denote the inputs of capital, labor, and land, respectively, and the parameter $\alpha \in(0,1)$ and $\gamma \in(0,1)$ measures the output shares of these production factors. Capital evolves according to:

$$
k_{t+1}=(1-\delta) k_{t}+i_{t}
$$

where $i_{t}$ is investment at time $t$ and $\delta$ is the depreciation rate. Note that $k_{t+1}$ is chosen at time $t$ and is predetermined at time $t+1$.

The firm starts each period with certain amount of land holding $l_{1 t}$, capital stock $k_{t}$, and intertemporal debt $b_{1 t}$. Its production revenue is given by $F\left(z_{t}, k_{t}, n_{t}, l_{1 t}\right)$. Dividend $d_{t}$ is distributed after making investment decisions $i_{t}$, debt issuance decisions $\frac{b_{1 t+1}}{R_{t}}$, and land allocation decisions $l_{1 t+1}$. Formally the firm's budget constraint is given by:

$$
b_{1 t}+d_{t}+i_{t}+p_{t}\left(l_{1 t+1}-l_{1 t}\right) \leq F\left(z_{t}, k_{t}, n_{1 t}, l_{1 t}\right)-w_{t} n_{1 t}+\frac{b_{1 t+1}}{R_{t}}
$$

The financial friction is modeled similar to Mendoza (2010), Jermann and Quadrini (2012), and Bianchi (2016). Besides issuing intertemporal debt, the firm needs to raise funds with an intraperiod loan to finance working capital. Working capital is required to cover cash flow mismatch between the payments made to workers, shareholders, bond holders and land holders at the beginning of the period and the realization of production revenues $F\left(z_{t}, k_{t}, n_{1 t}, l_{1 t}\right)$ at the end of the period. Firm's total borrowing capacity is limited by a fraction of the collateral asset:

$$
\frac{b_{1 t+1}}{R_{t}}+F\left(z_{t}, k_{t}, n_{1 t}, l_{1 t}\right) \leq \xi_{1 t} p_{t} l_{1 t+1}+\kappa_{t} k_{t+1}
$$

Under this credit constraint, the firm's borrowing capacity is limited by a fraction of the value of the collateral assets-land and capital. Note that the price of capital is equal to one as there is no variation in the marginal cost of capital. As is standard in the literature, I interpret this types of 
credit constraint as capturing the problem of costly contract enforcement: if the firm chooses to default and fails to repay the debt, the creditor can seize the collateral assets which are land and capital. Since it is costly to liquidate the seized assets, the creditor can recover only up to a fraction of the total values of land and capital. For generalization purposes I allow different pledgeability for land and for capital, proxied by $\xi_{1 t}$ and $\kappa_{t}$ respectively. The coefficients $\left(\xi_{1 t}, \kappa_{t}\right)$, together with the coefficient on the household's borrowing constraint, can be time-varying and their fluctuations are interpreted as "credit shocks" (Jermann and Quadrini, 2012).

Typically, models with firm-side borrowing constraints need some additional forces to prevent the firm from issuing too much equity. Otherwise the borrowing constraints cannot be binding in equilibrium as the firm always can turn to the equity market for financing. Such an equity issuance constraint is not required here because the household is also borrowing-constrained. The household-side borrowing constraint effectively puts an upper bound on how much resources the household can transfer to the firm through equity issuance, thus serving as an "endogenous" equity issuance constraint. As shown in the characterization section, the household-side and firm-side borrowing constraint always bind at the same time (proposition 2.2).

The firm's objective is to maximize the discounted value of dividend streams

$$
\max _{\left\{b_{1 t+1}, k_{t+1}, l_{1 t+1}, i_{t}, n_{1 t}, d_{t}\right\}} E \sum_{t=0}^{\infty} M_{t} d_{t}
$$

subject to the budget constraint equation 2.3; the law of motion for capital equation 4; the collateral constraint 2.4. The stochastic discount factor $M_{t}$ is equal to the household's equilibrium marginal utility of consumption. We now turn to describing the household's problem.

Household Sector The representative household's utility function is a generalized version of the Greenwood-Hercowitz-Huffman (GHH) preference, incorporating a taste for land services $l_{2 t}$ :

$$
U\left(c_{t}-G\left(n_{2 t}\right), l_{2 t}\right)
$$

The advantage of using a GHH specification is that it deliver realistic responses of employment over the business cycle without introducing additional labor market frictions which complicates the analysis. A critical parameter for the analysis is the degree of complementarity between consumption and land. Thus, we propose a constant elasticity of substitution form(CES form) with respect 
to the (composite) consumption and land services:

$$
U\left(\hat{c}_{t}, l_{2 t}\right)=\frac{\left[\omega \hat{c}_{t}^{1-1 / \sigma}+(1-\omega) l_{2 t}^{1-1 / \sigma}\right]^{\frac{1-1 / \eta}{1-1 / \sigma}}}{1-1 / \eta}
$$

Where $\hat{c}_{t}$ denotes composite consumption $c_{t}-G\left(n_{2 t}\right) . \omega$ is the preference weight on consumption. When $\omega=1$, it becomes a standard GHH preference. $\eta$ measures the intertemporal elasticity of substitution across different periods. $\sigma$ denotes the intratemporal elasticity of substitution between (composite) consumption and land services. When $\sigma$ is small, consumption and land are less substitutable, or equivalently, more complementarity.

The household starts each period with certain amount of land holding $l_{2 t}$ and bonds $b_{2 t}$. His income include labor income $w_{t} n_{2 t}$ and capital income $d_{t}$. In each period he chooses consumption and next period land and bond holdings subject to the following budget constraint:

$$
b_{2 t}+c_{t}+p_{t}\left(l_{2 t+1}-l_{2 t}\right) \leq d_{t}+w_{t} n_{2 t}+\frac{b_{2 t+1}}{R_{t}}
$$

Like the firm, the household is also constrained in borrowing and can use his land holding as collateral:

$$
\frac{b_{2 t+1}}{R_{t}} \leq \xi_{2 t} p l_{2 t+1}
$$

We do not allow the household to accumulate capital. This assumption is made without loss of generality as capital yields additional productive value if owned by the firm.

The household's problem is to maximize his discounted lifetime utility:

$$
\max _{\left\{b_{2 t+1}, l_{2 t+1}, c_{t}, n_{2 t}\right\}} E \sum_{t=0}^{\infty} \beta^{t} U\left(c_{t}-G\left(n_{2 t}\right), l_{2 t}\right)
$$

Subject to the budget constraints 2.8 and the collateral constraint 2.9 and given initial land and bond holdings. $\beta \in(0,1)$ is the discount factor.

Market Clearing and Equilibrium A competitive equilibrium is defined in a standard way in which the firm and the households maximize their respective objectives given market prices, and the markets for goods, labor, land and bonds all clear. Goods market clearing condition implies that:

$$
c_{t}+i_{t}=y_{t}
$$


Where $y_{t}$ denotes aggregate output at time $t$ and is equal to $F\left(z_{t}, k_{t}, n_{1 t}, l_{1 t}\right)$. Labor market clearing implies that:

$$
n_{1 t}=n_{2 t}
$$

Land market clearing implies that:

$$
l_{1 t}+l_{2 t}=\bar{L}
$$

bonds market clearing implies that:

$$
b_{1 t}+b_{2 t}=0
$$

Lastly, the firm's pricing kernel is equal to the household's marginal utility:

$$
M_{t}=\beta^{t} U_{c t}
$$

\subsection{Optimality Conditions}

In this section I examine the household's and the firm's optimality condition. Let $\mu_{t}^{f}$ be the multiplier associated to the firm's budget constraint 2.3 and $\mu_{t}^{h}$ to the household's budget constraint 2.8. It is easy to show that in equilibrium they are both equal to the household's discounted marginal utility of consumption. Thus we can label this common multiplier $\mu_{t}$ :

\section{Proposition 2.1}

$$
\mu_{t}^{h}=\beta^{t} U_{c t}=M_{t}=\mu_{t}^{f}:=\mu_{t}
$$

The first equality follows from household first order condition; the second equality is by definition of equilibrium; and the third equality follows from firm first order condition. Thus, we denote $\mu_{t}$ as the unified multiplier for both the household's and the firm's budget constraint. Let $\mu_{t} \lambda_{t}^{f}$ and $\mu_{t} \lambda_{t}^{h}$ be the multipliers on the firm's credit constraint 2.4 and the household's credit constraint 2.9 respectively. The multiplier is normalized by $\mu_{t}$ to simplify the exposition.

Then the firm's first order conditions(FOC) are given by:

$$
\begin{array}{rlrl}
\left(F_{n t}-w_{t}\right) \mu_{t} & =F_{n t} \mu_{t} \lambda_{t}^{f} & \text { (labor } \left.n_{1 t}\right) \\
\mu_{t} & =E_{t}\left[\mu_{t+1}\left(\left(1-\lambda_{t+1}^{f}\right) F_{k t+1}+(1-\delta)\right)\right]+\kappa_{t} \mu_{t} \lambda_{t}^{f} & & \text { (capital } \left.k_{t+1}\right) \\
\frac{\mu_{t}}{R_{t}} & =E_{t}\left[\mu_{t+1}\right]+\frac{\mu_{t} \lambda_{t}^{f}}{R_{t}} & & \text { (bonds } \left.b_{1 t+1}\right) \\
p_{t} \mu_{t} & =E_{t}\left[\mu_{t+1}\left(\left(1-\lambda_{t+1}^{f}\right) F_{l t+1}+p_{t+1}\right)\right]+\xi_{1 t} p_{t} \mu_{t} \lambda_{t}^{f} & & \text { (land } \left.l_{1 t+1}\right)
\end{array}
$$


Where $F_{x t}$ is the partial derivative of the production function with respect to $x$ and substitute in time $t$ variables. As in Jermann and Quadrini (2012), Bianchi (2016), and Mendoza (2010), the credit constraint is closely related to the labor wedge. To see this, note that the first order condition for labor $n_{1 t}$ implies:

$$
\lambda_{t}^{f}=\frac{F_{n t}-w_{t}}{F_{n t}}
$$

A binding credit constraint $\left(\lambda_{t}^{f}>0\right)$ implies a strictly positive wedge between the marginal product of labor and wage, because the firm is constrained in hiring. Thus, the credit constraint not only impacts investment but also have a direct effect on output through the labor channel. This implies that the collateral constraint can have big impact on output.

The household's first order conditions are given by:

$$
\begin{aligned}
w_{t} U_{c t} & =U_{n t} & & \left(\text { labor } n_{2 t}\right) \\
\frac{\mu_{t}}{R_{t}} & =E_{t}\left[\mu_{t+1}\right]+\frac{\lambda_{t}^{h} \mu_{t}}{R_{t}} & & \left(\text { bonds } b_{2 t+1}\right) \\
p_{t} \mu_{t} & =E_{t}\left[U_{l t+1}+\mu_{t+1} p_{t+1}\right]+\xi_{2 t} p_{t} \lambda_{t}^{h} \mu_{t} & & \text { (land } \left.l_{2 t+1}\right)
\end{aligned}
$$

Where $U_{x t}$ denotes the partial derivative of the utility function with respect to $x$ and substitute in time $t$ variables.

Comparing household's first order conditions and the firm's first order conditions deliver some interesting observations. First, compare the firm's first order condition for bonds $b_{1 t+1}$ and household's first order condition for bonds $b_{2 t+1}$, one get:

$$
\frac{\lambda_{t}^{f} \mu_{t}}{R_{t}}=\frac{\lambda_{t}^{h} \mu_{t}}{R_{t}}
$$

With regular utility function, $\mu_{t}$ and $R_{t}$ are always strictly positive. This implies the following proposition:

Proposition 2.2 the firm's credit constraint 2.4 binds if and only if the household's credit constraint 2.9 binds:

$$
\lambda_{t}^{f}=\lambda_{t}^{h}:=\lambda_{t}
$$

In this model, the household is the owner of the firm and there is no friction in transferring resources through equity. Suppose that the firm's collateral constraint is binding but the household's 
constraint is not. Then the household would transfer resource to the firm through equity issuance. This allows the firm to purchase additional financial asset (bonds) so as to relax its collateral constraint. Likewise, if the household's collateral constraint is binding but the firm's is not, the firm would increase its dividend payout to the household allowing him to relax his collateral constraint. Thus, the collateral constraint of both parties has to bind at the same time. In view of this result, we write $\lambda_{t}$ as the unified multiplier on both the firm's and the household's collateral constraint.

Sum up the household's and the firm's collateral constraint:

$$
\frac{b_{1 t+1}+b_{2 t+1}}{R_{t}}+F\left(z_{t}, k_{t}, n_{1 t}, l_{1 t}\right) \leq \xi_{1 t} p_{t} l_{1 t+1}+\xi_{2 t} p l_{2 t+1}+\kappa_{t} k_{t+1}
$$

Substituting in the bonds market clearing $b_{1 t+1}+b_{2 t+1}=0$, we arrive at an aggregate collateral constraint where production is financed jointly by the household and the firm:

$$
F\left(z_{t}, k_{t}, n_{1 t}, l_{1 t}\right) \leq \xi_{1 t} p_{t} l_{1 t+1}+\xi_{2 t} p l_{2 t+1}+\kappa_{t} k_{t+1} \quad \text { (aggregate collateral constraint) }
$$

The household's borrowing capacity matters for the firm because the more the household is able to borrow, the more financial assets the firm can accumulate. This relaxes the firm's collateral constraint and allows for more working capital financing and hence higher output. This implies that a household's side credit crunch could also lead to decrease in employment and output through the firm's balance sheet, consistent with Giroud and Mueller (2017).

Because the household's and the firm's collateral constraint bind at the same time, this could affect the steady-state interest rate. To see this, note that in a nonstochastic steady state, we can write the bond's first order condition as:

$$
\frac{1}{R}=\beta+\frac{\lambda}{R}
$$

where we get rid of all the time subscripts. This first order condition is the same for both the household and the firm. This equation implies that there is a negative relation between steadystate interest rate and tightness of the collateral constraint:

Proposition 2.3 The steady-state interest rate is decreasing in the tightness of the collateral constraint (measured by $\lambda$ )

$$
R=\frac{1-\lambda}{\beta}
$$


Suppose in some steady state the collateral constraint does not bind, then the interest rate $R$ is equal to $1 / \beta$ as in a standard model. If the collateral constraint does bind, there would be a positive labor wedge $w<F_{n}$ (equation 2.16). As a result both the household and the firm have extra incentives to accumulate financial assets, and this drives up asset prices and pushes down the interest rate. Note that this effect cannot arise when the collateral constraint is imposed only on one party, in which case the steady-state interest rate is always pinned down by the discount factor of the unconstrained agent.

In view of this proposition, an important feature of the model is that a constrained steady state, if it exists, tends to have lower interest rate than an unconstrained steady state. In the next section, we show that such steady states indeed exist.

\section{Steady State Analysis}

In this section we illustrate the steady state multiplicity and characterize condition under which multiple steady states arise. We start by laying out the steady state conditions:

Proposition 3.1 A nonstochastic steady state $\left(c, k, n, l_{1}, l_{2}, p, \lambda\right)$ is characterized by the following equations:

$$
\begin{aligned}
& p=\beta\left[(1-\lambda) F_{l}\left(z, k, n, l_{1}\right)+p\right]+\xi_{1} p \lambda \\
& p=\beta\left[\frac{U_{l}}{U_{c}}\left(c, l_{2}, n\right)+p\right]+\xi_{2} p \lambda \\
& 1=\beta\left[(1-\lambda) F_{k}\left(z, k, n, l_{1}\right)+(1-\delta)\right]+\kappa \lambda \\
& 0=\lambda\left[\xi_{2} p l_{2}+\xi_{1} p l_{1}+\kappa k-F\left(z, k, n, l_{1}\right)\right], \lambda \geq 0 \\
& \lambda=\frac{F_{n}\left(z, k, n, l_{1}\right)-\frac{U_{n}}{U_{c}}\left(c, l_{2}, n\right)}{F_{n}\left(z, k, n, l_{1}\right)} \\
& c=F\left(z, k, n, l_{1}\right)-\delta k \\
& \bar{L}=l_{1}+l_{2}
\end{aligned}
$$

The first two equations (equation 3.1 and 3.2) are the intertemporal first order conditions of land for the firm and for the household respectively. For the firm, purchasing land today at price $p$ (The LHS of equation 3.1) yields three benefits: future productive value (adjusted for the collateral constraint) $\beta(1-\lambda) F_{l}\left(z, k, n, l_{1}\right)$, future capital gain $\beta p$, and collateral value $\xi_{1} p \lambda$ if the constraint is binding. Likewise for the household, purchasing land yields intrinsic consumption value, future 
capital gain, and possibly collateral value. Equation 3.3 is the intertemporal first order condition for capital with an additional term $\kappa \lambda$ capturing the collateral value of capital.

Equation 3.4 is the complementary slackness condition on the aggregate collateral constraint. Note that there is no bond variables in this equation because any allocation that satisfies this aggregate collateral constraint can be decentralized with appropriate bond distribution. Equation 3.5 is the expression for the multiplier $\lambda$ on the aggregate collateral constraint. Equation 3.6 is the resource constraint and equation 3.7 represents land market clearing.

To characterize the steady state, we use the following strategy: fix any land price $p$, equations 3.1 through 3.6 solves allocation $\left(c, k, n, l_{1}, l_{2}, \lambda\right)$. This defines an implicit mapping from land prices to allocations. In particular, denote $l_{1}(p)$ and $l_{2}(p)$ as the implicit mapping from $p$ to $l_{1}$ and $l_{2}$. The interpretation of functions $l_{1}(p)$ and $l_{2}(p)$ is that they represent how firm's and household's demand for land varies with land price $p$ in steady states. Thus, we label $l_{1}(p)$ the firm's demand function and $l_{2}(p)$ the household's demand function. With these demand functions, we can define an aggregate land demand function $L(p)=l_{1}(p)+l_{2}(p)$.

Proposition $3.2 A$ vector $\left(c, k, n, l_{1}, l_{2}, p, \lambda\right)$ is a steady state if and only if the associated firm demand function and household demand function satisfy:

$$
L(p)=l_{1}(p)+l_{2}(p)=\bar{L}
$$

To proceed, we assume that the labor disutility function $G$ takes the following standard form:

Assumption 1 The labor disutility function $G$ takes the following form:

$$
G(n)=\chi \frac{n^{1+1 / \nu}}{1+1 / \nu}
$$

Where parameter $\nu$ is the Frisch elasticity of labor supply. This assumption will be maintained in the rest of the paper.

We start with the frictionless case where there is no collateral constraint, or equivalently when the set of loan to value ratios $\left(\xi_{1}, \xi_{2}, \kappa\right)$ are taken to infinity. Not surprisingly, in this case both the firm's demand and the household demand function are monotonically decreasing, reflecting the conventional price effect: demand for land decreases as its price increases. In particular, one can solve for steady state allocation independent of land prices and back out the land prices from equation 3.1 . 
Proposition 3.3 (Frictionless case) When there is no collateral constraints, there exists a unique frictionless steady state denoted by $\left(c_{s s}, k_{s s}, n_{s s}, l_{1 s s}, l_{2 s s}, p_{s s}\right)$. The land demand function is monotonically decreasing in land price $p$.

Next, we show that with collateral constraints, it is possible to obtain multiple steady states. Note that the whole system of equations is continuous and we already have a frictionless steady state, it suffices to show that there exists another (nontrivial) steady state using the following statement: there exists $p_{1}<p_{2}<p_{s s}$ such that $L\left(p_{1}\right)>0$ and $L\left(p_{2}\right)<0$. The easy part is to show that there exists $p_{1}$ such that $L\left(p_{1}\right)>0$ : take $p_{1}=0$; If $\kappa>0$, there will be positive output despite tight collateral constraint(equation 3.4); This implies infinite demand for land when its price $p_{1}=0$. The hard part is to show that there exists a $p_{2}$ such that $L\left(p_{2}\right)<0$. This is equivalent to proving that there exists an upward sloping proportion of the demand function. As shown by the following lemma, this upward-sloping proportion would come from household demand if consumption and housing are sufficiently complementary.

Lemma 3.1 Suppose $\sigma$ is sufficiently small. Then for some combination of loan to value ratios such that the collateral constraint just holds as equality at $p_{\text {ss }}$ (but not binding), the left derivative of household demand $l_{2}(p)$ at $p=p_{\text {ss }}$ is strictly positive:

$$
l_{2}^{\prime-}\left(p_{s s}\right)>0
$$

This lemma is the key theoretical result of the paper and requires that the consumption and land services are sufficiently complementary. To see the intuition, focus on the household first order condition for land (equation 3.2). Plug in the marginal rate of substitution between consumption and land into the equation, we obtain:

$$
p=\beta\left[\frac{1-\omega}{\omega}\left(\frac{\hat{c}}{l_{2}}\right)^{\frac{1}{\sigma}}+p\right]+\xi_{2} p \lambda
$$

where $\hat{c}$ denotes composite consumption $c-\chi \frac{n^{1+1 / \nu}}{1+1 / \nu}$. Rearrange this equation, one sees that the household demand for land depends on three aspects: consumption benefit, collateral benefit, and user cost:

$$
\underbrace{\beta \frac{1-\omega}{\omega}\left(\frac{\hat{c}}{l_{2}}\right)^{\frac{1}{\sigma}}}_{\text {Consumption benefit }}+\underbrace{\xi_{2} p \lambda}_{\text {Collateral benefit }}-\underbrace{(1-\beta) p}_{\text {User cost }}=0
$$


This expression is intuitive. The household demands land as it provides valuable services and relaxes his borrowing constraint, and in equilibrium these benefits should equate the net cost (current price minus future discounted price) for holding the land. Note that, the magnitude of the consumption benefit depends on $\sigma$, which captures the degree of complementarity between (composite) consumption and land in the household utility function. To see this more clearly, move the collateral benefit term and the net cost term to the right hand side and power both sides with $\sigma:$

$$
\left(\beta \frac{1-\omega}{\omega}\right)^{\sigma} \frac{\hat{c}}{l_{2}}=\left[(1-\beta) p-\xi_{2} p \lambda\right]^{\sigma}
$$

As land and consumption becomes more complementarity $(\sigma \rightarrow 0)$, the right hand side $\left[(1-\beta) p-\xi_{2} p \lambda\right]^{\sigma} \rightarrow\left[(1-\beta) p-\xi_{2} p \lambda\right]^{0}=1$, implying that the household demand moves oneto-one with consumption. This is because the consumption benefit dominates the other two forces in determining household demand for land. To the extent that a reduction in land price tightens the collateral constraint and leads to lower output and hence lower consumption, the household demand for land would be upward-sloping with respect to land price. This is the "land consumption channel" depicted in figure 2.

It is perhaps suitable at this point to contrast the land consumption channel to existing models with financial frictions. As summarized in Quadrini (2011), models with financial frictions face two challenges in generating strong amplification and propagation. First, “...the direct effect of financial frictions is on investment, not on inputs of labor. This has the potential to generate large fluctuations in investments, but output is only marginally affected." Second, "typical macroeconomic models do not generate large asset price fluctuations" (Page 233, Quadrini 2011). These two concerns are exactly addressed by the two features of the land consumption channel (see figure 2). The working capital specification of the collateral constraint leads to a direct and large impact of land prices on output; a sufficiently high degree of complementarity between land services and consumption guarantees sizable fluctuations in asset (land) prices. Combining these two features, the land consumption channel generates strong amplification and propagation that leads to steady-state multiplicity.

In theory, large fluctuation in land prices can also originate from the firm sector. Consider the scenario that land is highly complementarity to other production inputs. This, similar to the land consumption channel, can also make the firm's demand for land sensitive to economic fundamental, leading to an upward-sloping demand function. A potential caveat with this approach is a lack 


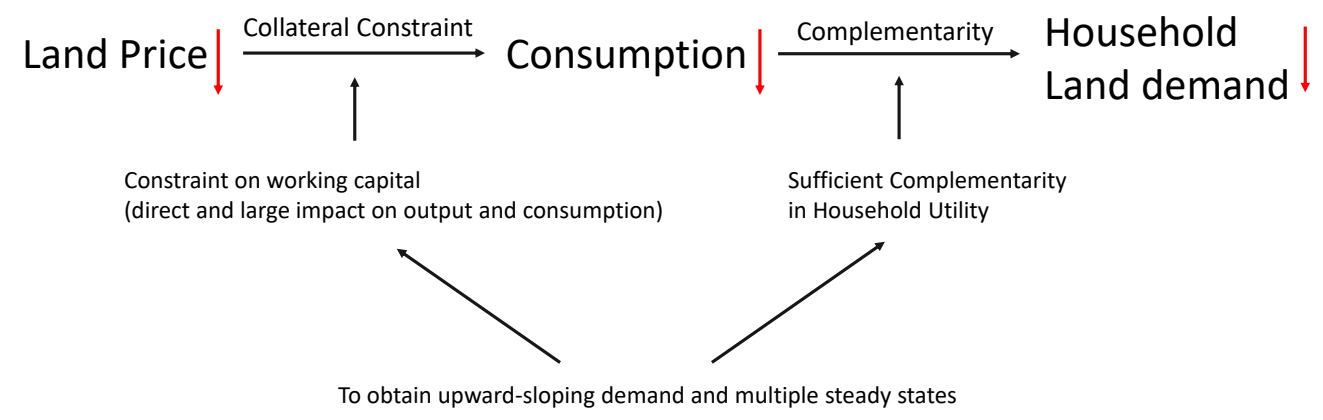

Figure 2: The Land Consumption Channel

of empirical estimates of this elasticity. While there is a literature studying empirical estimates of substitutability between capital and labor $^{8}$, few works, if at all, have tried to estimate the substitutability between land and other production inputs such as equipments and labor. Given the scarcity of empirical estimates, we adopt the conventional Cobb-Douglas production function which implicitly assumes a unity elasticity. Under this specification, firm's demand for land is always downward-sloping. Thus, for the aggregate demand to be upward sloping, we need the household demand component to overpower the firm component. This is guaranteed by 1) a sufficiently strong complementarity between consumption and land and 2) a sufficiently small land share in production function.

Theorem 1 Suppose $\sigma$ and $\gamma$ are sufficiently small. Then for some combination of loan-to-value ratios, there exists:

1. a unique unconstrained steady state, in which the collateral constraint is slack and

2. at least two constrained steady states, in which the collateral constraints are binding.

The theorem is illustrated in figure 3. It suffices to show that for some combination of the loan to value ratios, 1) the collateral constraint is slack at the frictionless steady state and 2) there exists some $p_{1}<p_{2}<p_{3}<p_{s s}$ such that $L\left(p_{1}\right)>0, L\left(p_{2}\right)<0$, and $L\left(p_{3}\right)>0$. This is depicted as the solid red curve in figure 3. These statements coupled with continuity implies that there exists a frictionless steady state A and two other constrained steady states B and C.

The hard part is to find a $p_{2}$ such that $L\left(p_{2}\right)<0$. To proceed we first consider an auxilary case where the collateral constraint just hold as equality at the frictionless steady state A. In this case we can show that the household demand function is upward-sloping at A by lemma 3.1 (blue dashed

\footnotetext{
${ }^{8}$ See, for example, Antràs (2004); Klump et al. (2007); Neiman and Karabarbounis (2014) and Oberfield and Raval (2014).
} 


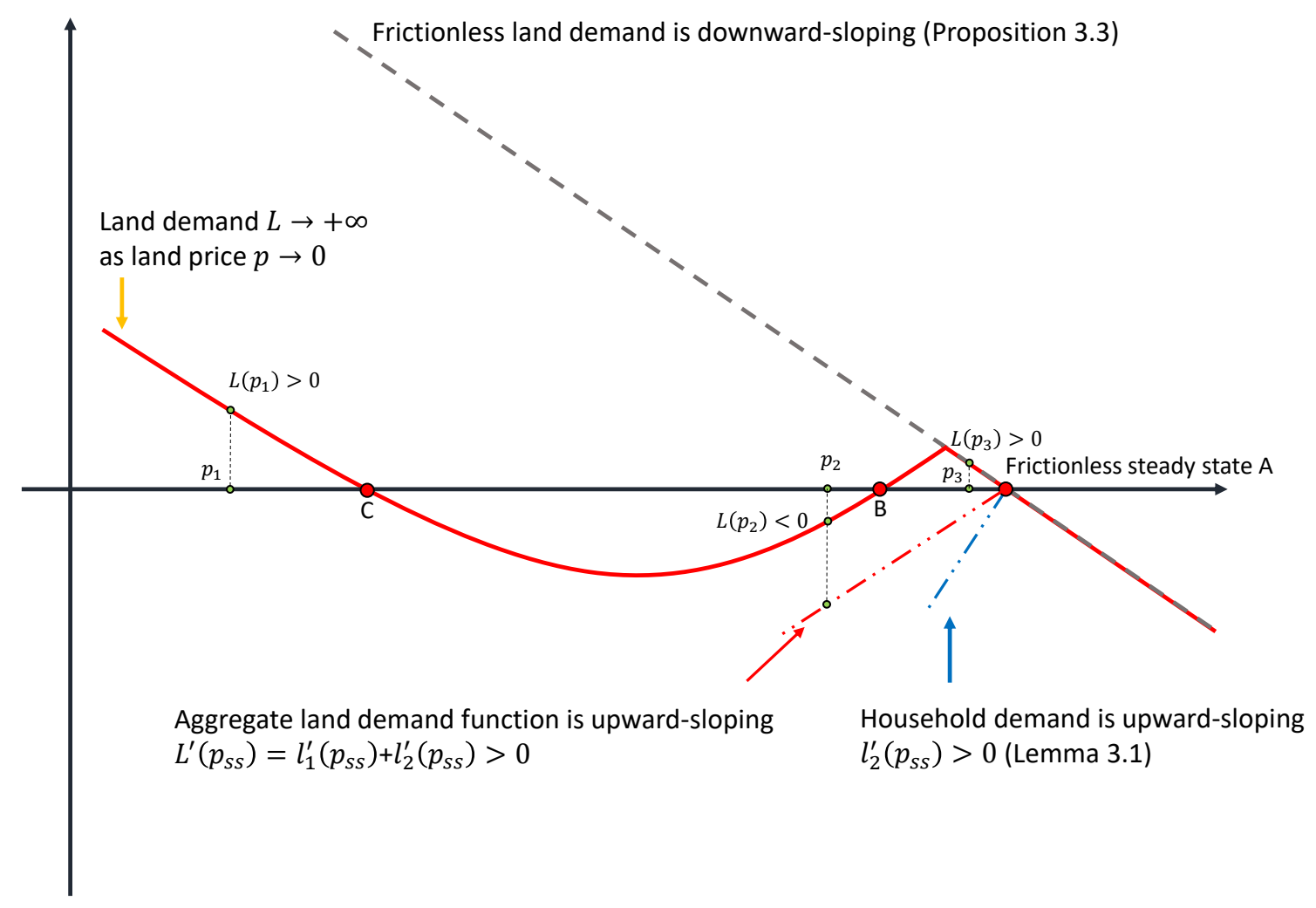

Figure 3: Graphical Illustration of Theorem 1

line). Thus the aggregate land demand is also upward-sloping (red dashed line) since the firm demand is dominated by the household demand, guaranteed by a sufficiently small land share $\gamma$. Thus we can pick a $p_{2}$ such that in this auxiliary case aggregate demand for land is upward-sloping.

By continuity, we can relax the collateral constraint by a little bit and $L\left(p_{2}\right)<0$ still holds. In this case where the collateral constraint is marginally relaxed, we can pick a value of $p_{3}$ sufficiently close to the frictionless level $p_{s s}$ such that the collateral constraint is slack. By proposition 3.3, land demand is monotonically decreasing if the collateral constraint slack (gray dashed line in figure 3). This implies that $L\left(p_{3}\right)>0$. Lastly, we turn to $p_{1}$. Note that when capital is pledgeable $\kappa>0$, output will be strictly positive even if land price $p$ tends to zero. As land is free and consumption is positive, demand for land tends to positive infinity. Thus we can pick $p_{1}$ sufficiently close to zero and get $L\left(p_{1}\right)>0$.

In view of proposition 2.3 , these steady states can be ranked in terms of interest rates.

Corollary 1 The interest rates of constrained steady states are lower than the interest rate of the unconstrained steady state. 
If a negative shock pushes the economy from the unconstrained steady state to the constrained one, then the transition would feature a secular decrease in interest rate, consistent with the "Secular Stagnation Hypothesis"(Summers, 2014). The low interest rate plays an important propagation role as it prevents the firm from saving out of the collateral constraint. Note that, at the constrained steady states the firm is a net lender $b_{1 t}<0$ and the household is a net borrower.

$$
b_{1 t}=-b_{2 t}=-R \xi_{2 t} p l_{2 t}<0
$$

The first equality follows from bond market clearing whereas the second equality comes from the binding collateral constraint. Although the firm can choose to accumulate financial assets, they are reluctant to do so as the return to financial assets is very low because of constrained demand for credit on the household side.

At the constrained steady state, the representative firm is always borrowing-constrained in terms of financing their working capital. This is not necessarily inconsistent with the fact that many corporations appear cash-rich and free from borrowing constraints during and after the Great Recession. While large corporations appear rich in liquidity, other firms such as the small and medium-sized enterprises and start-ups suffer from limits to borrowing. Moreover, the cash-hoarding behaviors of large corporations could be due to an insurance motive against the possibility of binding borrowing constraints in the future. Our story still holds if the insurance motive creates a sufficiently large wedge between the efficient level of investment/hiring and their actual level.

\section{Quantification}

This section describes the calibration strategy and presents the quantitative findings. The model is calibrated to the US economy and most of the model parameters are identified under the assumption that the economy is at the unconstrained steady state before the Great Recession, and at the stable constrained steady state after the recession. We verify ex-post that this is indeed the case. The discount factor $\beta$ is set to 0.99 as the model is calibrated to quarterly frequency. The intertemporal elasticity of substitution $\eta$ is set to standard value of 0.5 . The labor share $1-\alpha$ is set to 0.65 , or $\alpha=0.35$. The disutility from work parameter $\chi$ is set so that at the unconstrained steady state labor input is one third. The Frisch elasticity is set to infinity so that the labor cost function is linear as the indivisible labor case (Rogerson 1988; Hansen 1985). ${ }^{9}$ The preference

\footnotetext{
${ }^{9}$ Micro estimates of the Frisch elasticity are typically less than 1 . We will set Frisch elasticity to 0.4 in enriched version with wage rigidity.
} 
weight parameter $\omega$ and land share parameter $\gamma$ are calibrated to match: 1) the land value to GDP ratio of 1.07 and 2) the relative share of residential land (versus commercial land) of 0.55 . This leads to $\omega=0.27$ and $\gamma=0.086$. The implied gross share of land is $\gamma \alpha=0.0301$, consistent with values used by Liu et al. (2013) and Iacoviello (2005).

The key parameter is the intratemporal elasticity of substitution between consumption and housing services $\sigma$. While studies based on macro-level data find a value (slightly) greater than one (Davis and Martin, 2009 and Piazzesi, Schneider, and Tuzel, 2007), most studies based on microlevel data and structural estimation typically find a value between 0.1 and 0.6 (Hanushek and Quigley (1980), Flavin and Nakagawa, 2008, Siegel, 2008, Stokey, 2009, and Li, Liu, Yang, and Yao, 2016). I set $\sigma$ to 0.487 as in Li, Liu, Yang, and Yao (2016). The identification, as argued by Li, Liu, Yang, and Yao (2016), mainly comes from cross-sectional moments and relatively recent housing price data.

Next we focus on the collateral constraint. To start, we assume that for the firm land is as pledgeable as capital (Liu et al. 2013). Denote this common pledgeability parameter as $\xi_{2 t}$, we can write the aggregate collateral constraint as:

$$
F\left(z_{t}, k_{t}, n_{1 t}, l_{1 t}\right) \leq \xi_{1 t} p_{t} l_{1 t}+\xi_{2 t}\left(p_{t} l_{2 t}+k_{t+1}\right)
$$

We first calibrate the steady state loan-to-value ratio, $\xi_{1}$ and $\xi_{2}$. Because the collateral constraint does not bind at the unconstrained steady state, we cannot use empirical moments in normal times to calibrate these two parameters. Instead, we use post-recession moments to identify these two parameters: 1) ratio of post-recession output and pre-recession output of 94\%;2) relative borrowing between the household sector and the firm sector. The calibration is summarized in table 1.

Due to the nonlinear feature of the model, I largely follow the global method as in Bianchi (2016) to solve for the equilibrium. The numerical algorithm produces a unique recursive equilibrium with the law of motion for capital possessing multiple stationary points. As my main interest is in explaining the secular stagnation after the Great Recession, I compute a version of the model without aggregate uncertainty and then study model transitional dynamics after an unexpected credit shock that resembles the financial market turmoil during the recession.

\subsection{Quantitative Result}

The law of motion for capital is depicted in figure 4. The unique law of motion is S-shaped with three steady states. The top one and the bottom one are both locally stable. I label the top steady 
Table 1: Calibration

\begin{tabular}{llll}
\hline \multicolumn{1}{c}{ Parameters } & & Value & Source \\
\hline Discount factor & $\beta$ & 0.99 & Quarterly model \\
Intertemporal elasticity & $\eta$ & 0.5 & Standard \\
Disutility of working & $\chi$ & 2.41 & Steady state labor equal to .33 \\
Frisch Elasticity & $\nu$ & $\infty$ & Indivisible labor \\
Pref. weight & $\omega$ & 0.27 & Land value/GDP=1.06 \\
Depreciation & $\delta$ & $2.5 \%$ & Standard \\
Capital share & $\alpha$ & 0.35 & Standard \\
Land share & $\gamma$ & 0.086 & Relative share of commercial land \\
Intratemporal Elasticity & $\sigma$ & 0.487 & Micro estimates (e.g. Li et al. 2016) \\
Loan-to-value ratio & $\xi_{1}, \xi_{2}$ & $0.032,0.03$ & Post recession output gap and relative borrowing \\
Aggregate land stock & $\bar{l}$ & 1 & Normalization \\
\hline
\end{tabular}

state the "good steady state" and the bottom one the "bad steady state". The yellow dashed line depicts the law of motion for capital in a frictionless model without any collateral constraints. The local behavior of the model around the good steady state is identical to the frictionless model. When the level of capital declines, land price drops and the collateral constraints start binding. This leads to the S-shaped portion of the law of motion. When the level of capital is sufficiently low, the economy converges to the bad steady state. In summary, the economy displays nonlinear responses to shocks of different sizes. In particular, after a big financial crisis, capital stock gets destroyed. This tends to push the economy into the gray region and thus the economy would keep declining and finally converge to the bad steady state even if the negative shock completely goes away.

In figure 5, I solve for the transitional dynamics of the economy starting at different level of capital stock, as proxy for recessions of different sizes. This is to illustrate that the model implication on slow recovery is similar across different types of shocks, as long as they create similar level of capital losses. The economy recovers quickly after a small recession (yellow dashed line). In this scenario collateral constraint never binds and the economy behaves just as a frictionless growth model. Medium recessions (blue dashed line) take significant longer to recover. This is because it stucks at the constrained region(to the right of the middle unstable steady state in figure 4). Large recessions push the economy to the left of the middle unstable steady state. As a result, the economy drift to the bad steady state and never recovers.

For comparison purposes, I also present the transitional dynamics (figure 6) with a relatively high value of $\eta=0.8$, implying that consumption and land services are more substitutable. At this value of $\eta$ there is no multiple steady states. Nonetheless, the law of motion for capital is still 


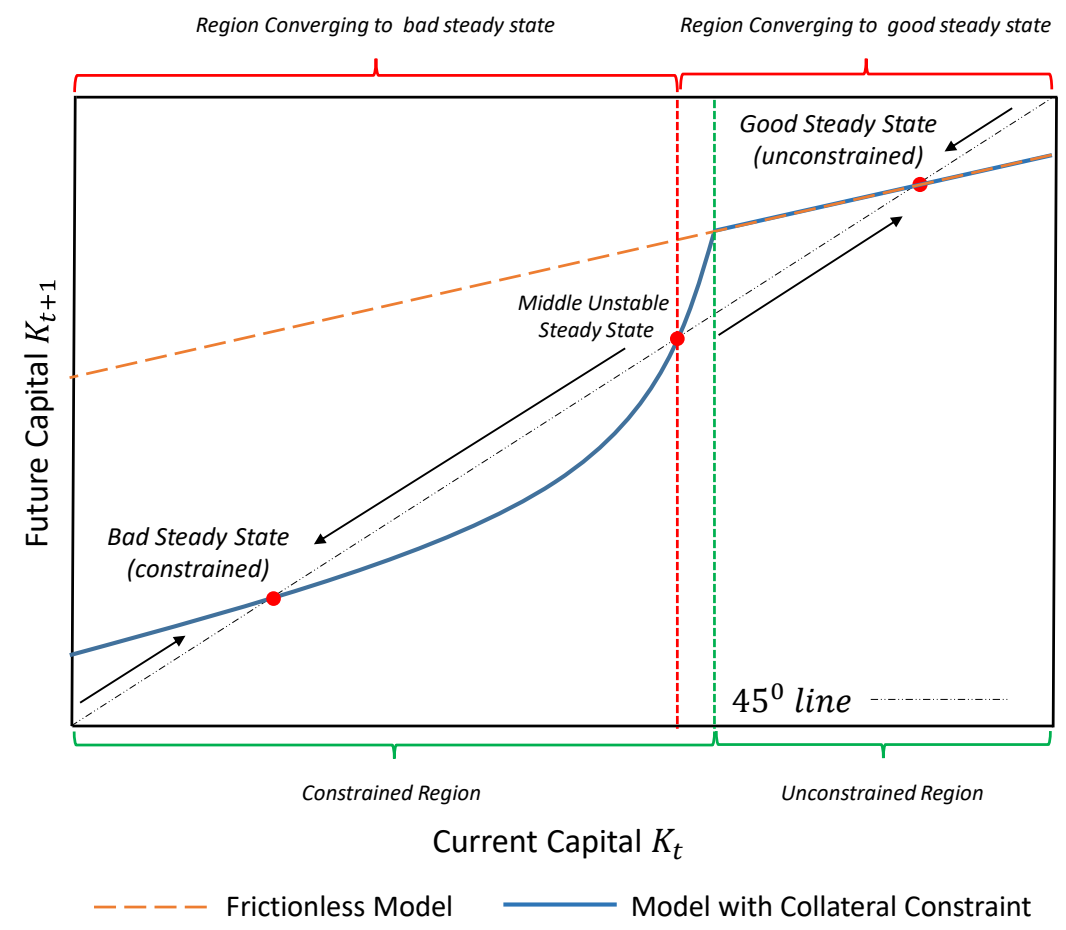

Figure 4: Law of Motion for Capital

S-shaped, leading to asymmetric recovery speed with respect to small and large recessions. After recessions that destroy a sufficient amount of capital stock, the economy experiences a prolonged recovery (red solid line and blue dashed line in figure 6).

The asymmetry patterns presented in figure 5 and figure 6 rely crucially on the movements of endogenous land price and the associated tightening of the collateral constraint. To illustrate, I consider an alternative specification where agents' borrowing capacity is evaluated according to a "fixed" land price $\bar{p}$ :

$$
F\left(z_{t}, k_{t}, n_{1 t}, l_{1 t}\right) \leq \xi_{1 t} \bar{p} l_{1 t}+\xi_{2 t}\left(\bar{p} l_{2 t}+k_{t+1}\right)
$$

I set the value of $\bar{p}$ to the unconstrained-steady-state level. Note that in this version land price is still endogenously determined by market clearing. However, the equilibrum land price is not used to evaluate borrowing capacity. Transitional dynamics of this "fixed-p economy" is presented in figure 7. The economy works just as a standard Real-business-cycle model with symmetric recovery speed across recessions of different sizes.

\section{Credit Shocks and the Great Recession}

In this part I use the quantitative model to answer the following question: could a severe but 
Figure 5: Transitional Dynamics Under Benchmark Calibration
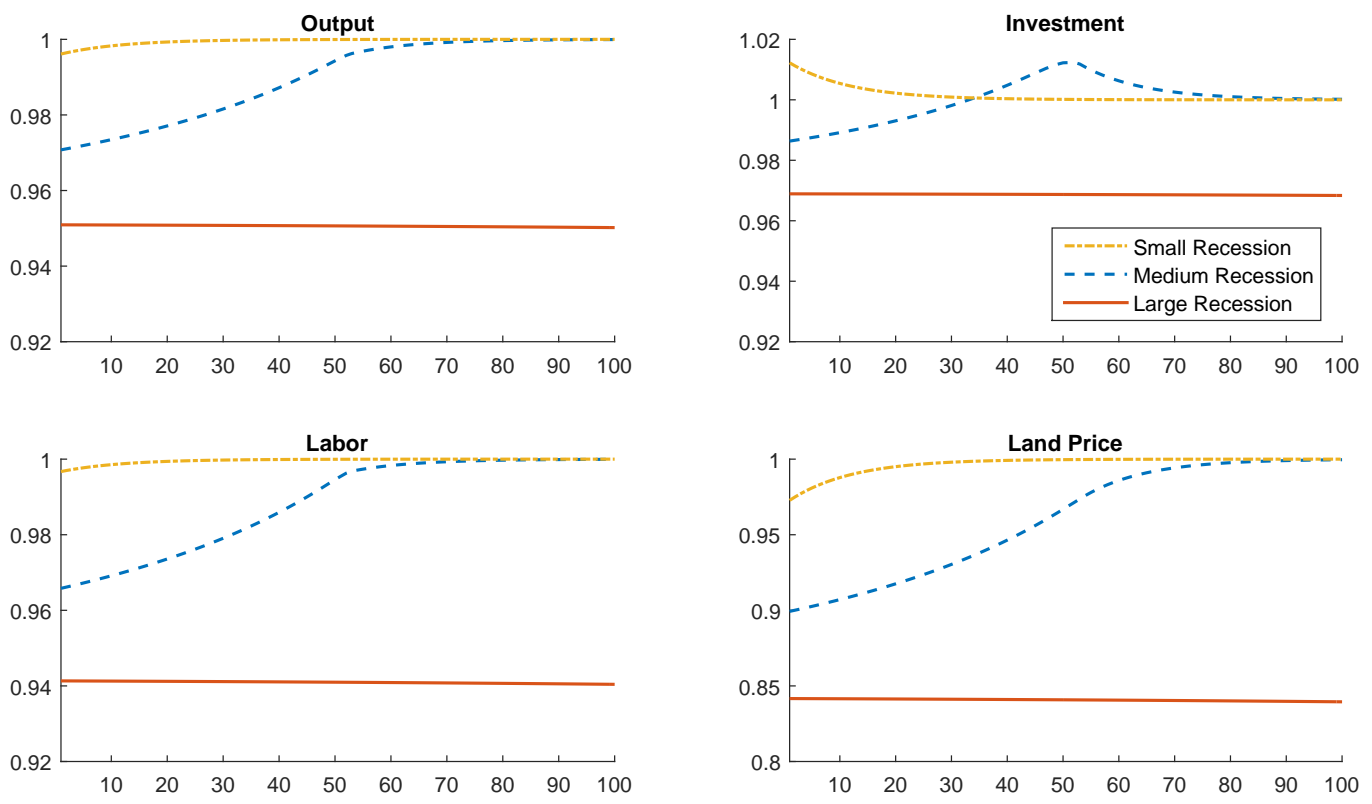

This figure plots transition starting with different levels of initial capital. Small recession starts with 99.5\% of unconstrained steady state capital. Medium recession starts at $98 \%$ and large recession starts at $96 \%$. The model displays asymmetric responses to recessions of different sizes.

Figure 6: Transitional Dynamics with Less Complementarity $\eta=0.8$


This figure plots transitional dynamics when land and consumption are more substitutable $\eta=0.8$. In this case there is no steady-state multiplicity but the law of motion for capital is still S-shaped. As a result, Medium and Large recessions (Blue dashed and red solid line) can still have prolonged impact on the economy. 
Figure 7: Transitional Dynamics in "Fixed-p" Economy
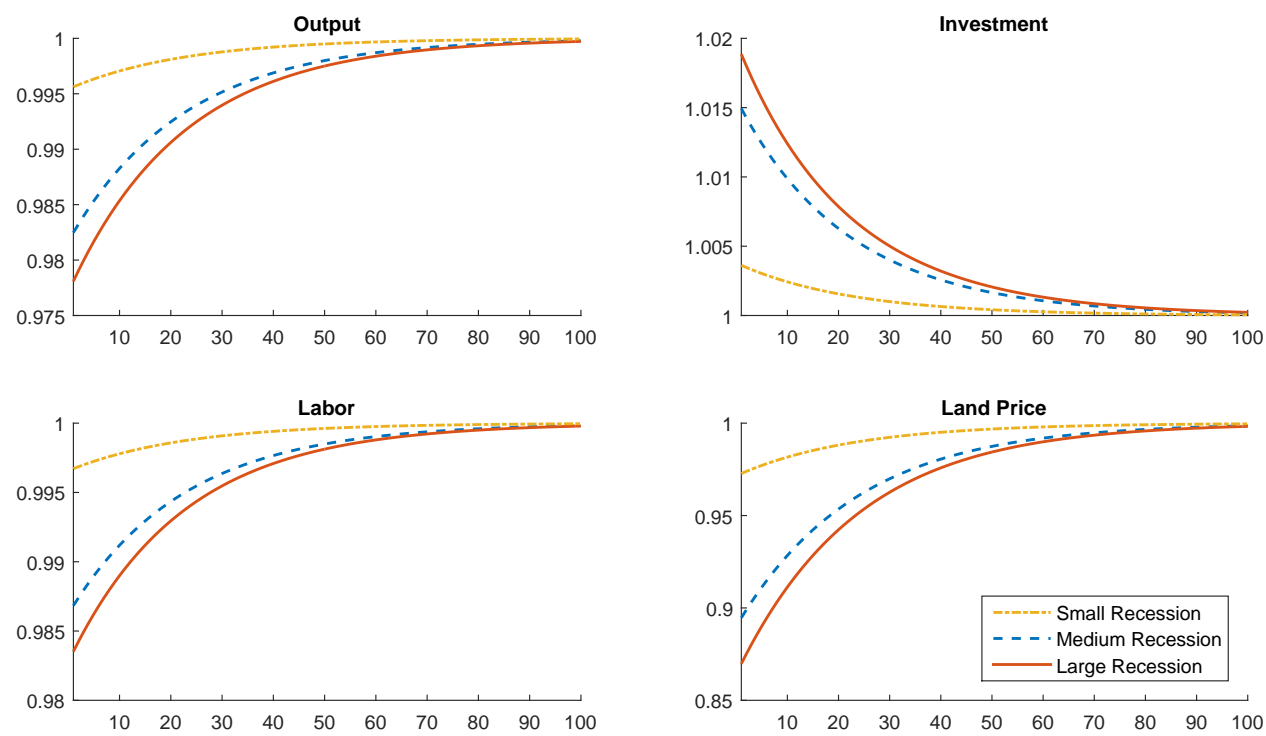

This figure plots transitional dynamics in an alternative model where price of land is fixed in the collateral constraint (land price is still determined in equilibrium but the quilibrium price is not used in the constraint). The asymmetric pattern disappears and the recovery speeds are broadly smilar across recessions of different sizes.

relatively short-lived financial market disturbances like what was observed in 2008-2009 have longlasting impact on the economy(Ohanian 2010)? I first follow Jermann and Quadrini (2012) and consider exogenous tightening of agents' borrowing constraints as a proxy for financial market distress. Specifically, I consider an unexpected reduction in the loan-to-value ratios $\xi_{1 t}$ and $\xi_{2 t}$ such that the land price drops by $25 \%$ during the Great Recession. The drops in $\xi_{1 t}$ and $\xi_{2 t}$ are equal percentage-wise and are both fully recovered by the second quarter of 2009 (Figure 8). ${ }^{10}$ The required decrease in the loan-to-value ratios is about $15 \%$.

I feed the series of credit shocks into the model and plot the responses of various macro aggregates in figure 9. The figure shows sharp drops in output, investment, and labor, followed by a quick reversion during the second half of the recession. This pattern within the recession closely mimic the behavior of the credit shock. ${ }^{11}$ When the credit shock vanishes in 2009, however, the economy settles on a permanently lower level of economic activities. This is because the large credit shock,

\footnotetext{
${ }^{10}$ We assume that the shock vanishes at constant rate and pick this rate such that $\xi_{1 t}$ and $\xi_{2 t}$ recovers to $99.95 \%$ of their respective pre-recession levels.

${ }^{11}$ As the focus of this paper is on post-recession recovery, we pick a simple exponentially vanishing credit shock to illustrate the model's ability to account for the secular stagnation that follows it. In the data, however, macro aggregates move more gradually in the beginning of the recession. This can be reconciled with a more gradual deterioration of the credit sector. Results would be similar in terms of recovery speed if similar amount of capital stock gets detroyed, as shown in figure 5 .
} 
Figure 8: Times Series of Credit Shocks $\xi_{1 t}, \xi_{2 t}$

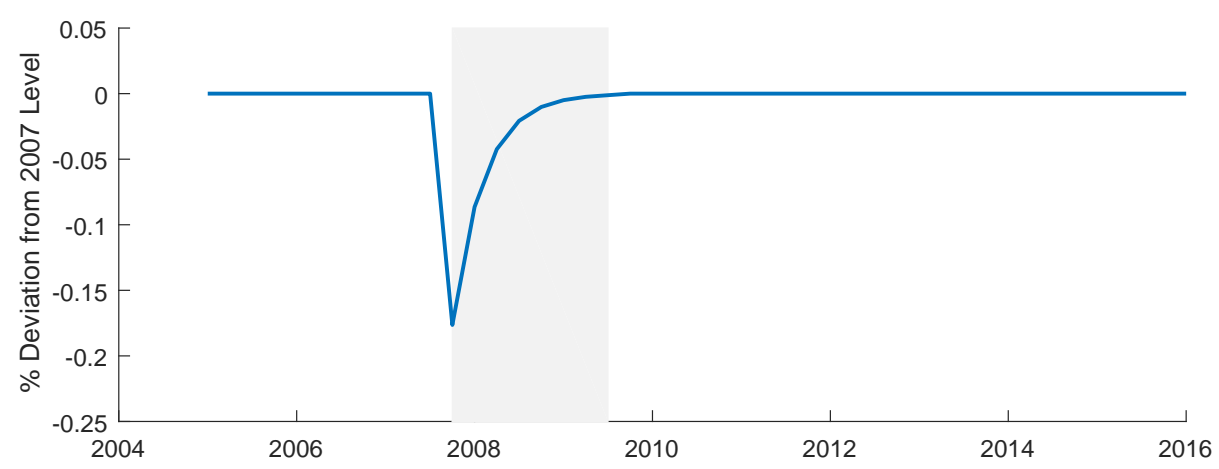

albeit temporary, leads to a drop in capital sufficiently big to trigger a shift from the unconstrained steady state to the constrained steady state (see figure 4).

The model is broadly consistent with the behavior of various macro variables in the recovery phase. It does well in matching the slow recovery pattern of labor. It also roughly matches the behavior of land price. It captures to some extent the slow recovery in output, but fails to account for its gradual decline after the recession. ${ }^{12}$ In terms of investment, the model predicts a decline and recovery that are both too sharp relative to the data. But the variations in physical capital is similar in magnitude. Overall the quantitative experiment suggests that a severe temporary credit shock similar to what we observed in 2008 is able to generate secular stagnation with persistently low economic activities. Note that, as the economy is pushed to the constrained steady state, we would also observe a decline in the real interest rate (Proposition 2.3).

\subsection{Extended Model with Wage Rigidity and Productivity Shocks}

The simulation result from the last section predicts that the economy would settle at the bad steady state with all macro aggregates converging to a permanently lower level. This is roughly in line with the data, but with some notable discrepancies. First, detrended output seems to keep declining after the recession. Second, labor (hours) seems to have a slow but gradual recovery (figure 1). I thus consider an extended model with additional layers of realism. First, I consider variations in productivity and feed the productivity series of Fernald (2012) into the model. This helps to explain the declining aggregate output as productivity growth has been weak since the end of the recession. Second, I incorporate a down-ward wage rigidity constraint. This serves two purposes. First, it allows me to use a much lower value of Frisch elasticity of labor supply in line

\footnotetext{
${ }^{12}$ The post-recession decline in output could be due to a secular decline in aggregate productivity. We will turn to this issue in the next section.
} 
Figure 9: Responses to Credit Shocks in Benchmark Model
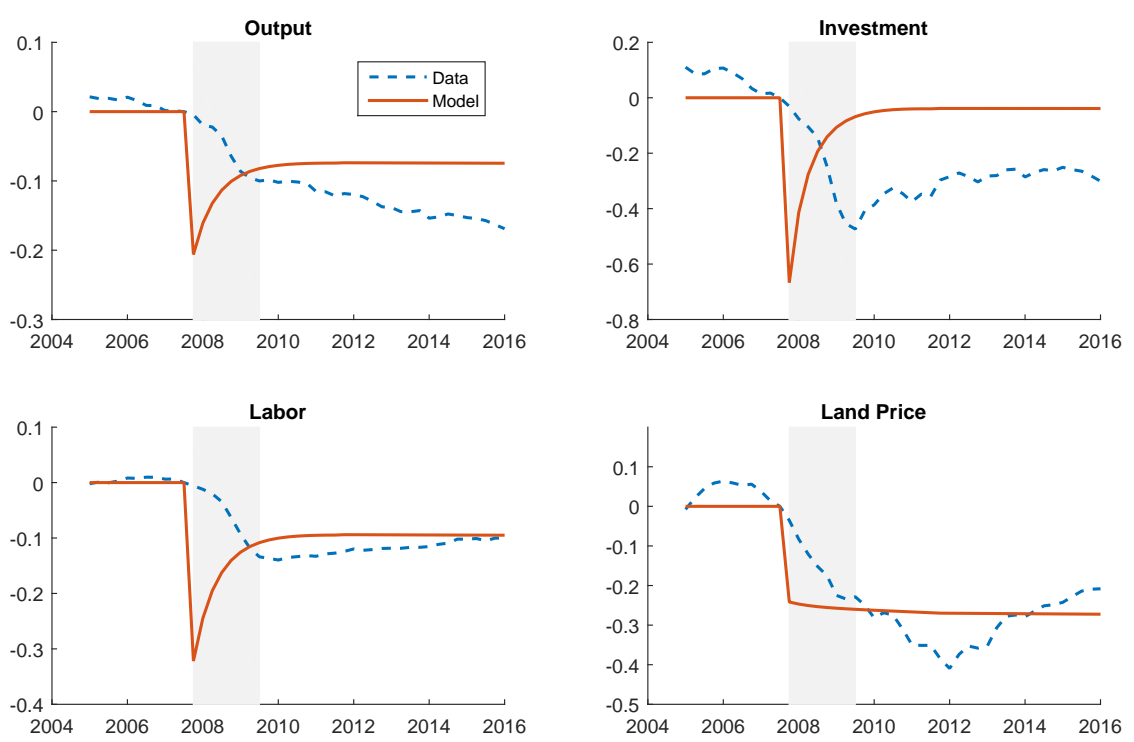

with the micro data, and still obtain significant stagnation after the Great Recession. Second, it accounts for the slow and gradual recovery of labor as the wage rate slowly adjusts over time. The extended model also allows me to decompose the sources of stagnation into two components, one due to the weak growth in productivity (Benigno and Fornaro 2018) and the other due to the internal propagation driven by the land consumption channel. I conclude that both productivity decline and the land consumption channel are important drivers of the secular stagnation, with the latter playing more important role before 2013 and the impact of productivity decline picked up after that.

I introduce the following downward wage-rigidity constraint:

$$
w_{t} \geq \zeta w_{t-1}
$$

The wage adjustment parameter $\zeta$ is set to $\left(\frac{1}{1+2 \%}\right)^{1 / 4} \approx 0.995$. This captures the idea that households are unwilling to accept nominal wage cuts and the inflation rate is around $2 \%$. Note that calibrating $\zeta$ with $2 \%$ annual inflation serves as a conservative benchmark given that inflation has been low in recent years. If inflation is lower, real wage would display greater stickiness, strengthening our mechanism. Daly, Hobijn, and Lucking (2012) documents that wage growth has been strong since the recession started, exactly because inflation has been low. Thus our quantitative results can be thought of as a lower bound on the strength of our mechanism. The wage rigidity 
Figure 10: Times Series of Productivity Shocks $z_{t}$

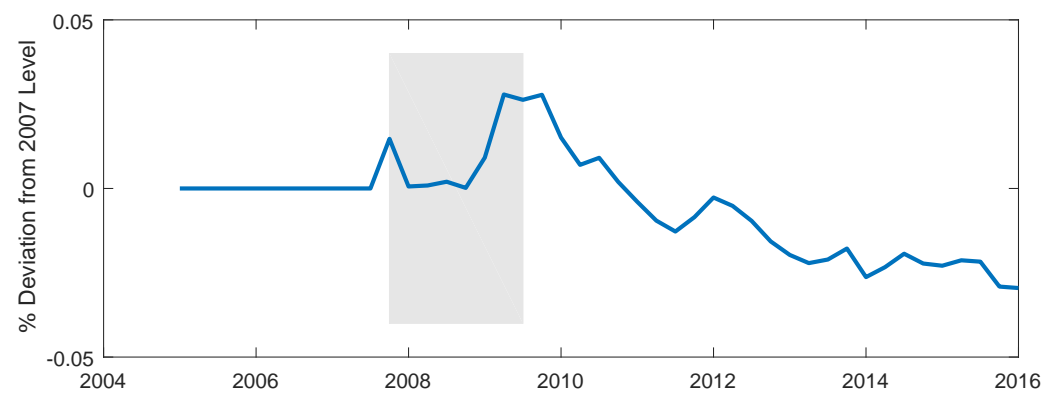

constraint implies that substantial economic stagnation can result even with relatively low values of Frisch elasticity, as the response of labor supply is almost irrelevant within an extended period of time after the recession due to the binding wage rigidity constraint. I set Frisch elasticity to 0.4, consistent with micro estimates. Other than this, I keep all the model parameters the same as in table 1.

In terms of productivity shocks, I use the productivity time series constructed by Fernald (2012) to calibrate productivity shocks (figure 10). I assume that the economy is at the unconstrained steady state before 2008 and considers both credit shocks (figure 8) and productivity shocks (figure 10) after that. As there is no significant decline in productivity within the recession, the behavior of the model between year 2008 and 2010 are very close to figure 9 . Thus, to focus on recovery patterns, I plot the model responses starting from year 2010 in figure 11 . Table 2 presents some formal statistics regarding recovery speeds of all variables presented in figure 11 . Relative to the first calibration with no wage rigidity and credit shocks only, the extended model has an improved quantitative performance in several dimensions. The extended model is able to match the gradual decline in detrended output after the recession. This is mainly because of the weak productivity growth as show in figure 10. The model is also able to match exactly the behavior of labor, in particular its small and gradual recovery (bottom right panel of table 2). This is due to the slow adjustment of wage rates arising from the wage rigidity constraint. As real wage decreases slowly, labor recovers a bit in response. The model also does a good job predicting land prices and investment at relatively longer horizon.

The literature has proposed that the secular stagnation is a result of weak productivity growth after the recession (see, for example, Benigno and Fornaro, 2018). I thus conduct a decomposition exercise to study how the internal propagation mechanism proposed in this paper contributes to the secular stagnation, in addition to productivity decline. The yellow solid line in figure 12 plots how macro aggregates recover with the productivity shocks held constant. It is labeled as "credit 
Figure 11: Simulation with both Productivity and Credit Shocks


This figure presents simulation results and compares them with the data starting in the year 2010. The data part I use the same time series as in Figure 1. For the model part, I feed in the series of productivity shocks as in figure 10 and credit shocks as in figure 8.

\begin{tabular}{rrrrrrrr} 
& \multicolumn{3}{c}{ Output } & & \multicolumn{3}{c}{ Investment } \\
\cline { 2 - 4 } \cline { 6 - 8 } Year & 2011 & 2013 & 2015 & & 2011 & 2013 & 2015 \\
\hline Data & $-12.7 \%$ & $-35.5 \%$ & $-49.7 \%$ & & $2.9 \%$ & $26 \%$ & $35 \%$ \\
Model & $-10.7 \%$ & $-18.8 \%$ & $-25.6 \%$ & & $-54.4 \%$ & $-90.0 \%$ & $-112 \%$
\end{tabular}

\begin{tabular}{rrrrrrrr} 
& \multicolumn{3}{c}{ Labor } & & \multicolumn{3}{c}{ Land Price } \\
\cline { 2 - 4 } \cline { 6 - 8 } Year & 2011 & 2013 & 2015 & & 2011 & 2013 & 2015 \\
\hline Data & $4.9 \%$ & $15.2 \%$ & $26.9 \%$ & & $-24 \%$ & $-25 \%$ & $13.9 \%$ \\
Model & $5.9 \%$ & $17.9 \%$ & $28.0 \%$ & & $3.4 \%$ & $10 \%$ & $18.6 \%$ \\
\hline
\end{tabular}

Note: the rate of recovery is calculated as the percentage of declined variables recovered relative to the fourth quarter of 2009. For instance, in $20114.9 \%$ of the declined labor was recovered (bottom left panel). The rate of recovery for output is negative as detrened output kept declining after the recession. The model did a particularly good job in matching the behavior of labor. It also predicts the declining post recession output and the pace of recovery for land price at longer horizon.

Table 2: Comparing Rate of Recovery (Model vs. Data) 

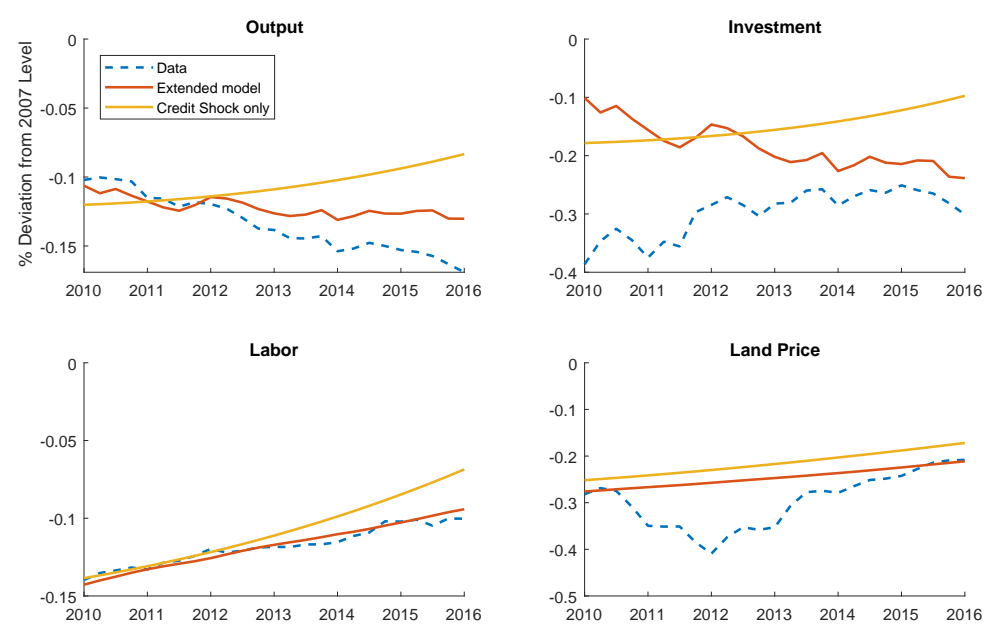

This figure presents simulation results and compares them with the data. For the data part I use the same time series as in Figure 1. For the model part, I feed in the series of productivity shocks as in figure 10 and credit shocks as in figure 8. In the "Credit Shock only" case, productivity is held constant and only credit shocks are considered.

Figure 12: Simulation

shock only". Relative to the benchmark model, the model with only credit shocks predicts quicker recovery of all four variables. Note that, the recovery pattern is very close to the benchmark model before 2013. After 2013, recovery speed starts to pick up with only credit shocks. This is due to the wage rigidity constraint being relaxed over time. I conclude that the extended model can explain a significant part of the secular stagnation, particularly before 2013. Weak productivity growth plays an important role over longer horizon.

\section{Conclusion}

This paper proposes and quantifies a theory in which financial frictions and land price dynamics propagate a temporary crisis event into a prolonged stagnation. The strong propagation comes from the high sensitivity of land prices with respect to economic fundamental. This sensitivity comes from a land consumption channel which exploits the fact that land and consumption are highly complementarity in the households' preferences. After quantifying the land consumption channel with micro-level evidence, I find that the model is capable of generating a secular stagnation similar to the data. The mechanism is also consistent with the persistent surge in labor wedge and decrease in interest rate. It also predicts that land price drops are correlated with speed of recovery, consistent with cross-sectional evidence in Schott (2015). 
The theoy is presented in a purposefully simple framework with a representative firm. At the constrained steady state, the representative firm is always borrowing-constrained. This is not necessarily inconsistent with the fact that many corporations appear cash-rich and free from borrowing constraints during and after the Great Recession. Firstly, while large corporations appear rich in liquidity, other firms such as the small and medium-sized enterprises and start-ups suffer from limits to borrowing. Second, the cash-hoarding behaviors of large corporations could be due to an insurance motive against the possibility of binding borrowing constraints in the future. Our story still holds if the insurance motive creates a sufficiently large wedge between the efficient level of investment/hiring and their actual level. To explore these we need a richer model with firm dynamics which is beyond the scope of this paper. We leave it to future research.

\section{References}

Antràs, Pol. "Is the U.S. aggregate Production Function Cobb-Douglas? New Estimates of the Elasticity of Substitution." Contributions in Macroeconomics, 4(2004).

Bajari, Patrick, Phoebe Chan, Dirk Krueger, and Daniel Miller. "A Dynamic Model of Housing Demand: Estimation and Policy Implications." International Economic Review, 54(2013), 409442.

Benigno, Gianluca and Luca Fornaro. "Stagnation Traps." The Review of Economic Studies, 85(2018), 1425-1470.

Bernanke, Ben and Mark Gertler. "Agency Costs, Net Worth, and Business Fluctuations." American Economic Review, 79(1989), 14-31.

Bianchi, Javier. "Efficient Bailouts?" American Economic Review, 106(2016), 3607-59.

Bianchi, Javier and Enrique G. Mendoza. "Optimal Time-Consistent Macroprudential Policy." Journal of Political Economy, 126(2018), 588-634.

Cerra, Valerie and Sweta Chaman Saxena. "Growth Dynamics: The Myth of Economic Recovery." American Economic Review, 98(2008), 439-57.

Cordoba, Juan-Carlos and Marla Ripoll. "Credit Cycles Redux." International Economic Review, 45(2004), 1011-1046.

Daly, Mary C., Bart Hobijn, and Brian Lucking. "Why has wage growth stayed strong?" FRBSF Economic Letter, (2012). 
Davis, Morris A. and Jonathan Heathcote. "The price and quantity of residential land in the United States." Journal of Monetary Economics, 54(2007), 2595-2620.

Davis, Morris A. and Robert F. Martin. "Housing, home production, and the equity- and valuepremium puzzles." Journal of Housing Economics, 18(2009), 81-91.

Eggertsson, Gauti B., Neil R. Mehrotra, and Jacob Robbins. "A Model of Secular Stagnation: Theory and Quantitative Evaluation." American Economic Journal: Macroeconomics, (2019).

Eggertsson, Gauti B., Neil R. Mehrotra, and Lawrence H. Summers. "Secular Stagnation in the Open Economy." American Economic Review, 106(2016), 503-07.

Fajgelbaum, Pablo, Edouard Schaal, and Mathieu Taschereau-Dumouchel. "Uncertainty traps." The Quarterly Journal of Economics, (2017).

Fernald, John G. "A quarterly, utilization-adjusted series on total factor productivity." (2012).

Flavin, Marjorie and Shinobu Nakagawa. "A Model of Housing in the Presence of Adjustment Costs: A Structural Interpretation of Habit Persistence." American Economic Review, 98(2008), 474-95.

Giroud, Xavier and Holger M. Mueller. "Firm Leverage, Consumer Demand, and Employment Losses During the Great Recession." The Quarterly Journal of Economics, 132(2017), 271-316.

Guerrieri, Luca and Matteo Iacoviello. "Collateral Constraints and Macroeconomic Asymmetries." Journal of Monetary Economics, 90(2017), 28 - 49.

Hansen, Gary D. "Indivisible labor and the business cycle." Journal of Monetary Economics, 16(1985), $309-327$.

Hanushek, Eric A and John M Quigley. "What Is the Price Elasticity of Housing Demand?" The Review of Economics and Statistics, 62(1980), 449-54.

Heathcote, Jonathan and Fabrizio Perri. "Wealth and Volatility." The Review of Economic Studies, 85(2018), 2173-2213.

Iacoviello, Matteo. "House Prices, Borrowing Constraints, and Monetary Policy in the Business Cycle." American Economic Review, 95(2005), 739-764.

Jermann, Urban and Vincenzo Quadrini. "Macroeconomic Effects of Financial Shocks." American Economic Review, 102(2012), 238-71.

Jordà, Òscar, Moritz Schularick, and Alan M. Taylor. "Leveraged bubbles." Journal of Monetary Economics, 76(2015), 1-20.

Kaplan, Greg and Guido Menzio. "Shopping Externalities and Self-Fulfilling Unemployment Fluctuations." Journal of Political Economy, 124(2016), 771-825. 
Kiyotaki, Nobuhiro and John Moore. "Credit Cycles." Journal of Political Economy, 105(1997), $211-48$.

Klump, Rainer, Peter McAdam, and Alpo Willman. "Factor Substitution and Factor-Augmenting Technical Progress in the United States: A Normalized Supply-Side System Approach." The Review of Economics and Statistics, 89(2007), 183-192.

Kocherlakota, Narayana R. "Creating business cycles through credit constraints." Quarterly Review, (2000), 2-10.

Li, Wenli, Haiyong Liu, Fang Yang, and Rui Yao. "Housing over time and over the life cycle: a structural estimation." International Economic Review, (2016).

Liu, Zheng, Jianjun Miao, and Tao Zha. "Land prices and unemployment." Journal of Monetary Economics, 80(2016), 86 - 105.

Liu, Zheng and Pengfei Wang. "Credit Constraints and Self-Fulfilling Business Cycles." American Economic Journal: Macroeconomics, 6(2014), 32-69.

Liu, Zheng, Pengfei Wang, and Tao Zha. "Land-Price Dynamics and Macroeconomic Fluctuations." Econometrica, 81(2013), 1147-1184.

Mendoza, Enrique G. "Sudden Stops, Financial Crises, and Leverage." American Economic Review, 100(2010), 1941-66.

Mian, Atif and Amir Sufi. "House Prices, Home Equity-Based Borrowing, and the US Household Leverage Crisis." American Economic Review, 101(2011), 2132-56.

—. "What Explains the 2007-2009 Drop in Employment?" Econometrica, 82(2014), 21972223.

Neiman, Brent and Loukas Karabarbounis. "The Global Decline of the Labor Share." The Quarterly Journal of Economics, 129(2014), 61-103.

Oberfield, Ezra and Devesh Raval. "Micro Data and Macro Technology." (2014).

Ohanian, Lee E. "The Economic Crisis from a Neoclassical Perspective." Journal of Economic Perspectives, 24(2010), 45-66.

Piazzesi, Monika, Martin Schneider, and Selale Tuzel. "Housing, consumption and asset pricing." Journal of Financial Economics, 83(2007), 531-569.

Quadrini, Vincenzo. "Financial frictions in macroeconomic fluctuations." Economic Quarterly, (2011), 97(3): 209-254.

Reinhart, Carmen M. and Kenneth S. Rogoff. "The Aftermath of Financial Crises." American Economic Review, 99(2009a), 466-72. 
—. "The Aftermath of Financial Crises." American Economic Review, 99(2009b), 466-72.

Rogerson, Richard. "Indivisible labor, lotteries and equilibrium." Journal of Monetary Economics, 21(1988), $3-16$.

Schmitt-Grohé, Stephanie and Martín Uribe. "Underborrowing." NBER Working Papers 22264, National Bureau of Economic Research, Inc (2018).

Schott, Immo. "Startups, Credit, and the Jobless Recovery." (2015).

Shimer, Robert. "Wage rigidities and jobless recoveries." Journal of Monetary Economics, 59(2012), S65-S77.

Siegel, Stephan. "Consumption-based asset pricing: durbale goods, adjustment costs, and aggregation." (2008).

Stokey, Nancy L. "Moving costs, nondurable consumption and portfolio choice." Journal of Economic Theory, 144(2009), 2419-2439.

Summers, Lawrence. "U.S. Economic Prospects: Secular Stagnation, Hysteresis, and the Zero Lower Bound." Business Economics, 49(2014).

Taschereau-Dumouchel, Mathieu and Edouard Schaal. "Aggregate Demand and the Dynamics of Unemployment." (2016a).

—. "Coordinating Business Cycles." (2016b). 


\section{A Appendix}

\section{A.1 Proposition 3.3}

A frictionless steady state $\left(c, k, n, l_{1}, l_{2}, p\right)$ is characterized by the same set of equations as in proposition 3.1, with $\lambda=0$ :

$$
\begin{aligned}
p & =\beta F_{l}+\beta p \\
p & =\beta \frac{U_{l}}{U_{c}}+\beta p \\
1 & =\beta\left[F_{k}+1-\delta\right] \\
F_{n} & =\frac{U_{n}}{U_{c}} \\
c & =F-\delta k \\
\bar{L} & =l_{1}+l_{2}
\end{aligned}
$$

Comparing the first equation and the second equation, one get that the marginal product of land has to be equal to the marginal rate of substitution:

$$
F_{l}=\frac{U_{l}}{U_{c}}
$$

Note that land price only shows up in the first and the second equation and gets cancelled out. Thus we arrive at a system of equation characterizing $\left(c, k, n, l_{1}, l_{2}\right)$ :

$$
\begin{aligned}
F_{l} & =\frac{U_{l}}{U_{c}} \\
1 & =\beta\left[F_{k}+1-\delta\right] \\
F_{n} & =\frac{U_{n}}{U_{c}} \\
c & =F-\delta k \\
\bar{L} & =l_{1}+l_{2}
\end{aligned}
$$

Denote the solution to this system of equation $\left(c_{s s}, k_{s s}, n_{s s}, l_{1 s s}, l_{2 s s}\right)$. The solution is the steady state allocation and it is not varying with the land price $p$. And we can back out $p_{s s}$

$$
p_{s s}=\frac{\beta F_{l}\left(z, l_{1 s s}, k_{s s}, n_{s s}\right)}{1-\beta}
$$




\section{A.2 Lemma 3.1}

We will show that for some combination of the loan-to-value ratios $\left(\xi_{1}, \xi_{2}, \kappa\right)$, the slope of the household demand function is positive at $p=p_{s s}$. We consider the case that $\kappa=0, \xi_{1}=\xi_{2}=\xi_{s s}=$ $\frac{F\left(z, k_{s s}, n_{s s}, l_{1 s s}\right)}{p_{s s} L}$, so that the collateral constraint holds with equality (but not binds):

$$
\xi_{1} p_{s s} l_{1 s s}+\xi_{2} p_{s s} l_{2 s s}=\xi_{s s} p_{s s}\left(l_{1 s s}+l_{2 s s}\right)=\xi_{s s} p_{s s} \bar{L}=F\left(z, k_{s s}, n_{s s}, l_{1 s s}\right)
$$

This implies that for any $p<p_{s s}$, the collateral constraint will be binding. To see this, suppose the contrary that the collateral constraint is slack. Then we know from proposition 3.3 that output will be

$$
F\left(z, k_{s s}, n_{s s}, l_{1 s s}\right)
$$

which is less than the borrowing capacity

$$
\xi_{s s} p \bar{L}<\xi_{s s} p_{s s} \bar{L}=F\left(z, k_{s s}, n_{s s}, l_{1 s s}\right)
$$

Thus, the borrowing constraint has to be binding for any $p<p_{s s}$. With the binding collateral constraint, we have

$$
\lambda=\frac{F_{n}-\frac{U_{n}}{U_{c}}}{F_{n}}=1-\frac{\chi n^{\frac{1}{\nu}}}{F_{n}}>0
$$

Plug this into the capital first order condition(note that $\kappa=0$ ):

$$
1=\beta\left[\chi^{\frac{1}{\nu}} \frac{F_{k}}{F_{n}}+1-\delta\right]
$$

due to the power production function,

$$
\frac{F_{k}}{F_{n}}=\frac{\alpha(1-\gamma) n}{(1-\alpha) k}
$$

Plug this into the first order condition

$$
1=\beta\left[\chi n^{\frac{1}{\nu}} \frac{\alpha(1-\gamma) n}{(1-\alpha) k}+1-\delta\right]
$$

Rearrange, we find a relation between capital and labor

$$
k=\theta_{k} n^{1+\frac{1}{\nu}}
$$


For some coefficient $\theta_{k}$.Plug this relation into the production function $F$

$$
\begin{aligned}
F & =z l_{1}^{\alpha \gamma} k^{\alpha(1-\gamma)} n^{1-\alpha} \\
& =z l_{1}^{\alpha \gamma}\left(\theta_{k} n^{1+\frac{1}{\nu}}\right)^{\alpha(1-\gamma)} n^{1-\alpha} \\
& =z \theta_{k}^{\alpha(1-\gamma)} l_{1}^{\alpha \gamma} n^{\alpha\left(1+\frac{1}{\nu}\right)(1-\gamma)+1-\alpha}=\xi_{s s} p \bar{L}
\end{aligned}
$$

where the last equality follows from a binding collateral constraint. This implies that labor is a power function of land price $p$ and firm holding of land $l_{1}$ :

$$
n=\theta_{n} p^{\frac{1}{\alpha\left(1+\frac{1}{\nu}\right)(1-\gamma)+1-\alpha}} l_{1}^{-\frac{\alpha \gamma}{\alpha\left(1+\frac{1}{\nu}\right)(1-\gamma)+1-\alpha}}
$$

For some coefficients $\theta_{n}$. In this proof, we will focus on the case where $\nu \rightarrow \infty$ and $\gamma \rightarrow 0$ to simplify notations. In this case

$$
n=\theta_{n} p
$$

and thus capital is also linear in $p$

$$
k=\theta_{k} \theta_{n} p
$$

This implies that the composite consumption

$$
\begin{aligned}
\hat{c} & =c-\chi \frac{n^{1+\frac{1}{\nu}}}{1+\frac{1}{\nu}} \\
& =F-\delta k-\chi \frac{n^{1+\frac{1}{\nu}}}{1+\frac{1}{\nu}} \\
& \rightarrow \xi_{s s} \bar{L} p-\delta \theta_{k} \theta_{n} p-\chi \theta_{n} p \\
& =\left(\xi_{s s} \bar{L}-\delta \theta_{k} \theta_{n}-\chi \theta_{n}\right) p \\
& =\theta_{c} p
\end{aligned}
$$

is linear in land price as well. Note that the coefficient $\theta_{c}$ must be strictly positive since $\theta_{c}=\frac{\hat{c}_{s s}}{p_{s s}}$. Now focus on the household land demand function

$$
p=\beta\left[\frac{1-\omega}{\omega}\left(\frac{\hat{c}}{l_{2}}\right)^{\frac{1}{\sigma}}+p\right]+\xi_{s s} p \lambda
$$

Plug in $\lambda$ and $\hat{c}$

$$
p=\beta\left[\frac{1-\omega}{\omega}\left(\frac{\theta_{c} p}{l_{2}}\right)^{\frac{1}{\sigma}}+p\right]+\xi_{s s} p\left(1-\frac{\chi n^{\frac{1}{\nu}}}{(1-\alpha) \frac{F}{n}}\right)
$$

Rearrange, we obtain

$$
p=\beta \frac{1-\omega}{\omega}\left(\frac{\theta_{c} p}{l_{2}}\right)^{\frac{1}{\sigma}}+\beta p+\xi_{s s} p-\xi_{s s} p \frac{\chi n^{1+\frac{1}{\nu}}}{(1-\alpha) \xi_{s s} \bar{L} p}
$$




$$
p=\beta \frac{1-\omega}{\omega}\left(\frac{\theta_{c} p}{l_{2}}\right)^{\frac{1}{\sigma}}+\beta p+\xi_{s s} p-\frac{\chi \theta_{n} p}{(1-\alpha) \bar{L}}
$$

Thus we have

$$
\left(\frac{\theta_{c} p}{l_{2}}\right)^{\frac{1}{\sigma}}=\theta_{h} p
$$

where $\theta_{h}$ is some constants. Note that the left hand side captures the consumption benefit term. An increase in land price $p$ should leads to greater household demand $l_{2}$. The right hand side captures the sum of the price effect and collateral benefit, and the net effect presumably is negative. When $\sigma \rightarrow 0$, the right hand side becomes inconcequential relative to the right hand side, thus this equation becomes:

$$
\frac{\theta_{c} p}{l_{2}}=1
$$

Thus

$$
\frac{d l_{2}}{d p}=\theta_{c}>0
$$

\section{A.3 Theorem 1}

As outlined in the main text, we need to find a combination of loan-to-value ratios, such that the resulting aggregate land demand function has the following property: 1) the collateral constraint is slack at $p_{s s}$ and 2) there exists $p_{1}<p_{2}<p_{3}<p_{s s}$ such that $p_{1}>0, p_{2}<0, p_{3}>0$.

We will start with picking the value of $p_{2}$ as it is the hardest part of the proof. We will consider the auxilary case where the collateral constraint just holds as equality:

$$
\xi_{1}=\xi_{2}=\xi_{s s}=\frac{F\left(z, k_{s s}, n_{s s}, l_{1 s s}\right)}{p_{s s} \bar{L}}, \kappa=0
$$

In this case we know that household demand for land is upward-sloping at $p_{s s}$. Next we show that firm's demand will be downward-sloping, but its strentgh depend on $\gamma$.

The firm demand for land is given by:

$$
p=\beta\left[(1-\lambda) F_{l}+p\right]+\xi_{s s} p \lambda
$$

Plug in expression of $\lambda=1-\frac{\chi n^{\frac{1}{\nu}}}{F_{n}}$

$$
p=\beta\left[\frac{\chi n^{\frac{1}{\nu}}}{F_{n}} F_{l}+p\right]+\xi_{s s} p\left(1-\frac{\chi n^{\frac{1}{\nu}}}{F_{n}}\right)
$$

Plug in expression for the marginal productivities, one obtains:

$$
p=\beta\left[\frac{\gamma(1-\alpha)}{\alpha} \frac{\chi n^{1+\frac{1}{\nu}}}{l_{1}}+p\right]+\xi_{s s} p\left(1-\frac{\chi n^{1+\frac{1}{\nu}}}{F}\right)
$$


Plug in expressions of $n$ and $F$ as functions of $p$ :

$$
\begin{aligned}
& p=\beta \frac{\gamma(1-\alpha)}{\alpha} \frac{\chi \theta_{n}}{l_{1}}+\beta p+\xi_{s s} p\left(1-\frac{\chi \theta_{n} p}{\xi_{s s} \bar{L} p}\right) \\
& p=\beta \frac{\gamma(1-\alpha)}{\alpha} \frac{\chi \theta_{n}}{l_{1}}+\beta p+\xi_{s s} p\left(1-\frac{\chi \theta_{n}}{\xi_{s s} \bar{L}}\right)
\end{aligned}
$$

This implies

$$
\begin{aligned}
p & =\beta \frac{\gamma(1-\alpha)}{\alpha} \frac{\chi \theta_{n}}{l_{1}}+\beta p+\xi_{s s} p\left(1-\frac{\chi \theta_{n}}{\xi_{s s} \bar{L}}\right) \\
\beta \frac{\gamma(1-\alpha)}{\alpha} \frac{\chi \theta_{n}}{l_{1}} & =\left(1-\beta-\xi_{s s}\left(1-\frac{\chi \theta_{n}}{\xi_{s s} \bar{L}}\right)\right) p \\
l_{1} & =\frac{\beta \gamma(1-\alpha) \chi \theta_{n}}{\alpha\left(1-\beta-\xi_{s s}\left(1-\frac{\chi \theta_{n}}{\xi_{s s} L}\right)\right) p}
\end{aligned}
$$

Thus the firm demand for land is always monotnically decreasing in land price $p$. But the slope vanishes as $\gamma \rightarrow 0$. Thus, when $\gamma$ is sufficiently small, the aggregate slope of land demand

$$
L^{\prime}\left(p_{s s}\right)=l_{1}^{\prime}\left(p_{s s}\right)+l_{2}^{\prime}\left(p_{s s}\right)>0
$$

This implies that we can pick a $p_{2}$ such that this auxilary aggregate demand function $L\left(p_{2}\right)<0$

Next we increase $\kappa$ by a marginal amount. This amount is sufficiently small so that $L\left(p_{2}\right)<0$ still holds. In this case output is strictly less than aggregate borrowing capacity at the frictionless steady state:

$$
F\left(z, k_{s s}, n_{s s}, l_{1 s s}\right)=\xi_{s s} p_{s s} \bar{L}<\xi_{s s} p_{s s} \bar{L}+\kappa k_{s s}
$$

where the first equality follows from the definition of $\xi_{s s}$ and the second inequality follows from $\kappa>0$ and $k_{s s}>0$. This implies that we can pick a $p_{3}$ sufficiently close to $p_{s s}$ such that for any value of $p \geq p_{3}$, the borrowing constraint is slack. Thus the behavior of the aggregate land demand function when $p \geq p_{3}$ is no different from the frictionless case. Thus we can invoke the proposition 3.3 particularly the monotonic decreasing property we have

$$
L\left(p_{3}\right)>L\left(p_{s s}\right)=0
$$

Lastly, we pick $p_{1}$. Given that $\kappa>0$, the economy can still produce strictly positive output even when land price $p \rightarrow 0$

$$
F=\kappa k>0
$$

This implies that consumption, labor, and capital are all bounded away from zero as $p \rightarrow 0$. Denote 
this limit allocation $\left(c_{0}, n_{0}, k_{0}\right)$.Plug this allocation into firm's demand:

$$
\begin{gathered}
p=\beta\left[(1-\lambda) F_{l}+p\right]+\xi_{s s} p \lambda \\
p=\beta\left[\frac{\chi n^{\frac{1}{\nu}}}{F_{n}} F_{l}+p\right]+\xi_{s s} p\left(1-\frac{\chi n^{\frac{1}{\nu}}}{F_{n}}\right) \\
p=\beta\left[\frac{\gamma(1-\alpha)}{\alpha} \frac{\chi n^{1+\frac{1}{\nu}}}{l_{1}}+p\right]+\xi_{s s} p\left(1-\frac{\chi n^{1+\frac{1}{\nu}}}{F}\right)
\end{gathered}
$$

With $p=0$, This expression becomes

$$
\beta \frac{\gamma(1-\alpha)}{\alpha} \frac{\chi n_{0}^{1+\frac{1}{\nu}}}{l_{1}}=0
$$

Thus, the firm's demand $l_{1}$ tends to positive infinity for the equation to hold. Similarly, one can check that the household demnd for land has to diverge to infinity as well. Thus we have $L(p=0)=+\infty$. 


\section{A.4 Various Graphs}

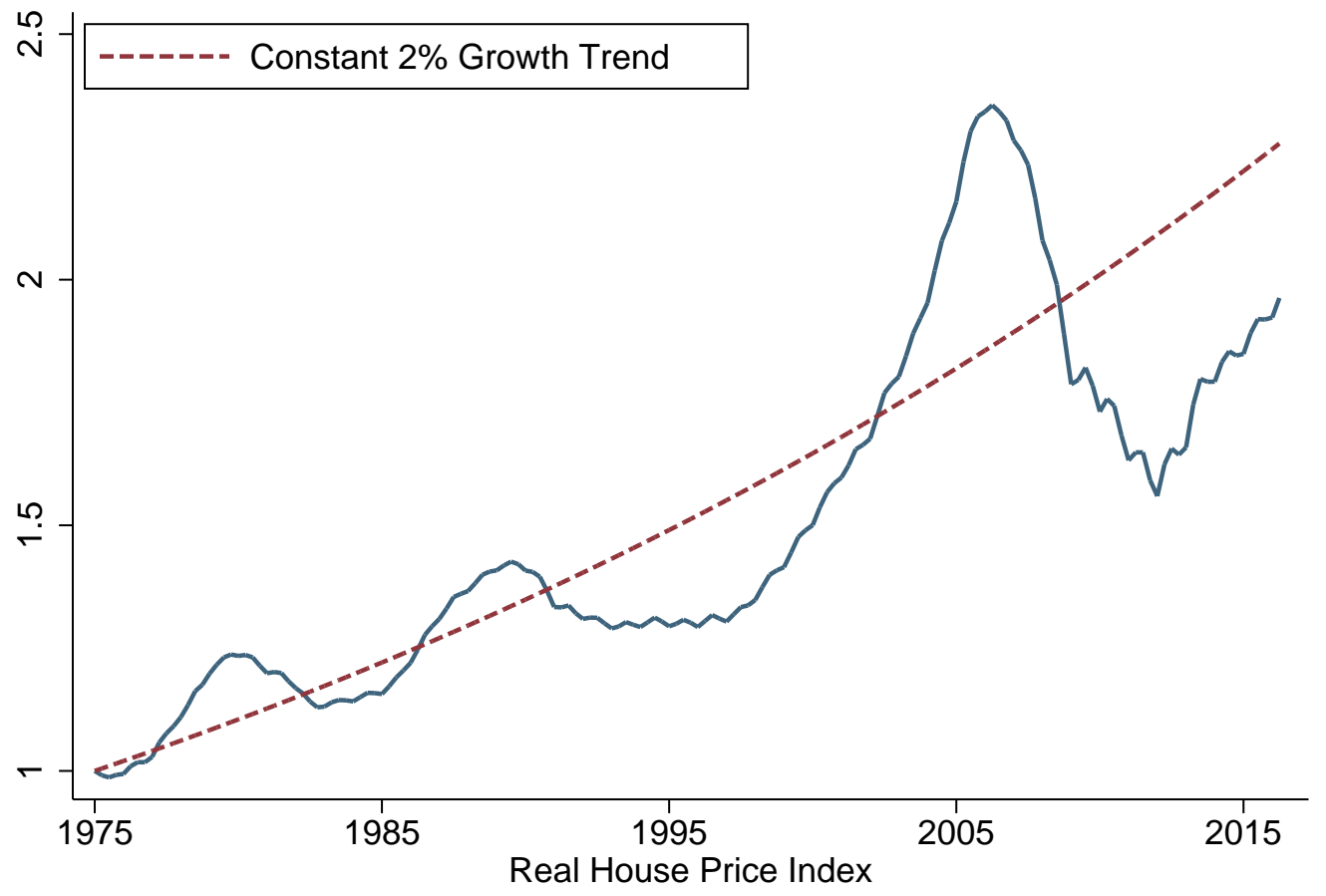

S\&P/Case-Shiller U.S. National Home Price Index, deflated by GDP deflator

This figure plots the S\&P/Case-Shiller U.S. National Home Price Index, deflated by the GDP deflator, along with its constant growth trend. The growth rate is picked to be $2 \%$, as in Heathcote and Perri (2018). This is the average growth rate for real GDP per capita between 1947 and $200 \%$. It is also close to the average growth rate for real house prices between 1975 and 2006 (see Figure 1 in Davis and Heathcote, 2007).

Figure 13: Real Housing Price and its trend 


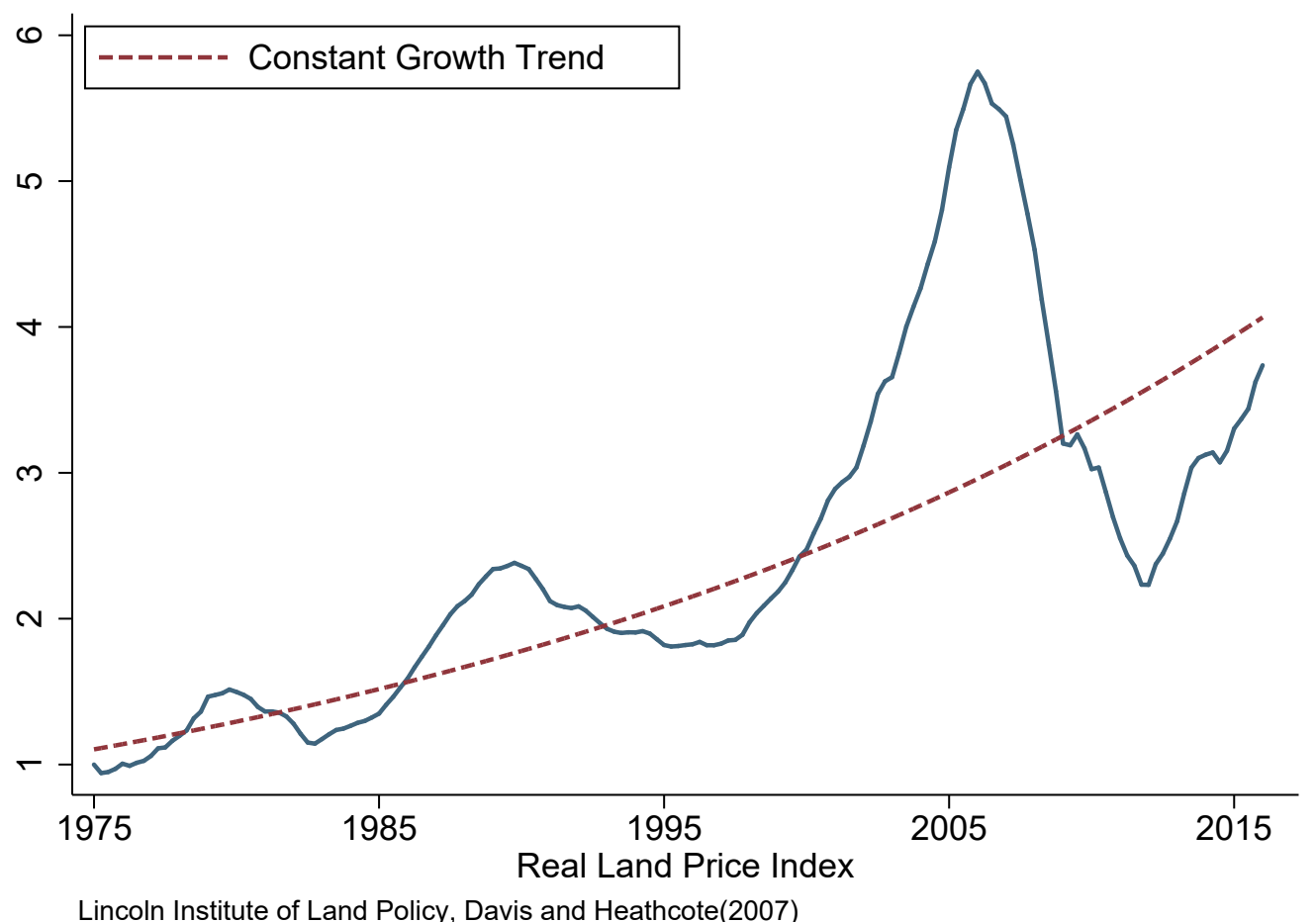

Lincoln Institute of Land Policy, Davis and Heathcote(2007)

This figure plots the land price index available from the Lincoln Institute of Land Policy, which is constructed following Davis and Heathcote (2007), using Case-Shiller National Home Price Index and replacement cost of structures available from BEA. The data is available at http://datatoolkits.lincolninst.edu/subcenters/land-values/price-and-quantity.asp. For the constant growth trend, the growth rate of the trend is picked to match the average growth rate of real land price between 1975 and 1995.

Figure 14: Real Land Price and its trend 